Review Article

\title{
The Good, the Bad, and the Ugly of ROS: New Insights on Aging and Aging-Related Diseases from Eukaryotic and Prokaryotic Model Organisms
}

\author{
Ana L. Santos $\mathbb{D}^{1},{ }^{1}$ Sanchari Sinha, ${ }^{2}$ and Ariel B. Lindner ${ }^{1}$ \\ ${ }^{1}$ Institut National de la Santé et de la Recherche Médicale, U1001 \& Université Paris Descartes, Sorbonne Paris Cité, Paris, France \\ ${ }^{2}$ Defence Institute of Physiology and Allied Sciences, DRDO, New Delhi, India \\ Correspondence should be addressed to Ana L. Santos; ana.santos@inserm.fr
}

Received 4 August 2017; Revised 18 December 2017; Accepted 2 January 2018; Published 18 March 2018

Academic Editor: Sergio Di Meo

Copyright ( 2018 Ana L. Santos et al. This is an open access article distributed under the Creative Commons Attribution License, which permits unrestricted use, distribution, and reproduction in any medium, provided the original work is properly cited.

\begin{abstract}
Aging is associated with the accumulation of cellular damage over the course of a lifetime. This process is promoted in large part by reactive oxygen species (ROS) generated via cellular metabolic and respiratory pathways. Pharmacological, nonpharmacological, and genetic interventions have been used to target cellular and mitochondrial networks in an effort to decipher aging and agerelated disorders. While ROS historically have been viewed as a detrimental byproduct of normal metabolism and associated with several pathologies, recent research has revealed a more complex and beneficial role of ROS in regulating metabolism, development, and lifespan. In this review, we summarize the recent advances in ROS research, focusing on both the beneficial and harmful roles of ROS, many of which are conserved across species from bacteria to humans, in various aspects of cellular physiology. These studies provide a new context for our understanding of the parts ROS play in health and disease. Moreover, we highlight the utility of bacterial models to elucidate the molecular pathways by which ROS mediate aging and aging-related diseases.
\end{abstract}

\section{Introduction}

Aging is characterized by a gradual loss of fitness over time. Aging is manifested as a series of dynamic changes at the molecular and macromolecular level over the course of a lifetime [1]. Faulty regulation of cellular processes can damage the cell's physiological integrity and subsequently lead to accumulation of damaged byproducts. Mankind has been fascinated with obtaining a better understanding of aging for many centuries, yet the exact mechanisms underlying the human aging process remain largely unclear. The aging process itself is complex due to several confounders, such as environmental factors, socioeconomic status, physical characteristics, and lifestyle [2].

Over the past few decades, life expectancy has increased linearly worldwide to an average of 60 years. The world's population over 60 is expected to increase from approximately 900 million people (12\%) in 2015 to approximately 2 billion people (22\%) in 2050 [3]. This increased life expectancy is associated with a reduced rate of child mortality, improved standards of living, and medical advancements, among others. Despite an increase in overall lifespan, aging and age-related diseases are major causes of mortality and morbidity worldwide [4]. Moreover, age-related disorders, such as Alzheimer's disease, dementia, cardiopulmonary disorders, diabetes, neurodegenerative and cognitive impairments, fragile physical condition, and psychosomatic disorders, are major causes of disability worldwide. These disorders account for over $20 \%$ of years lived with a disability [5]. Understanding the molecular mechanisms of aging is critical for developing therapeutic interventions that promote healthy aging.

Mitochondria often termed "the powerhouse of the cell," metabolize carbohydrates and fatty acids via oxidative phosphorylation. Through this process, the mitochondria can generate 32 to 34 adenosine triphosphate (ATP) molecules per molecule of glucose. The protein complexes in the inner mitochondrial membrane collectively form the 
mitochondrial electron transport chain (ETC), which releases free radicals as byproducts of energy metabolism [6]. Harman originally proposed the free radical theory of aging in 1956 [7], according to which reactive oxygen species (ROS) are the primary mediators of the aging process. A brief overview of the sources of ROS and subsequent cellular responses is provided in Figure 1. The sources of ROS, antioxidant defenses, and subsequent biological effects have been reviewed elsewhere (e.g., [8]) and will not be covered in depth in this review. While extensive evidence indicates that enhanced ROS production and decreased ROS-scavenging ability shortens lifespan [9, 10], the free radical theory of aging has faced opposition, undermining the idea that ROS alone are responsible for the aging process. For instance, organisms can live a healthy lifespan in the absence of ROS scavengers [11-14]. Further, nutritional, pharmacological, and genetic interventions that increase production of ROS can promote longevity by activating mitochondrial oxidative phosphorylation and triggering downstream signaling pathways that promote an adaptive response $[11,15,16]$, while pharmacological interventions that limit ROS production have been shown to shorten lifespan $[11,15]$.

While ROS and ROS-induced oxidative damage may not be the sole cause of the aging process, it is fairly consensual that ROS do play an important role in the molecular mechanisms that influence longevity. Thus, bridging the gap between the free radical theory and the current aging knowledge can help us to better understand how the interaction between ROS-induced oxidative damage and cellular metabolism affects aging and uncover genetic and pharmaceutical interventions that could modulate this interaction.

\section{The Free Radical Theory of Aging and Beyond}

Over the last few decades, the dominant aging model has been the free radical theory of aging. This theory states that organisms age because they accumulate oxidative damage produced by ROS. ROS are partially reduced metabolites of molecular oxygen generated by various metabolic reactions and cellular processes, such as respiration [11, 15]. Several studies support the free radical theory of aging. For instance, the garlic-derived thioallyl compounds S-allyl cysteine and S-allylmercaptocysteine have been shown to reduce ROS accumulation and increase C. elegans lifespan [17]. Similarly, treatment of $C$. elegans with four synthetic stilbene derivatives extended longevity by reducing ROS accumulation and oxidative stress [18].

However, recent research indicates that ROS play a more complex role in determining longevity than previously thought. For instance, C. elegans mutants lacking superoxide dismutase (SOD) - an enzyme that neutralizes the superoxide radical-while being more susceptible to multiple stressors, retain a normal lifespan [12]. In another study, deletion of the mitochondrial superoxide dismutase sod-2 was actually found to extend the lifespan of C. elegans [19]. Furthermore, C. elegans lacking functional genes for subunits of the mitochondrial respiratory chain complexes I and III produce higher levels of superoxide, but they also have an extended lifespan. The extended lifespan of these knockouts can be completely abolished by treating them with the superoxide scavenger $N$-acetylcysteine [20]. Additionally, when wild-type $C$. elegans and the long-lived clk-1 mitochondrial mutant were treated with paraquat, a superoxide generator, both the mean and maximum lifespan increased significantly [20].

2.1. Antioxidant Enzymes: Good or Bad? Antioxidant enzymes play a key role in the neutralization of various ROS. However, the relationship between antioxidant enzyme levels and lifespan is not straightforward.

Several studies investigating the role of the antioxidant defense system in regulating longevity have shown that increased resistance to oxidative stress can improve longevity in mice $[21,22]$. For instance, $\mathrm{Cu} / \mathrm{Zn}$ superoxide dismutase 1 knockout $\left(\operatorname{Sod} 1^{-1-}\right)$ mice have significantly decreased lifespans. This reduced lifespan was associated with increased cellular senescence based on the increased expression of the senescence markers p16 and p21 [23]. Further, mitochondrial catalase overexpression has been connected to the increased median and maximum lifespan in transgenic mice overexpressing peroxisomal, nuclear, and mitochondrial catalases [24]. Mitochondrial catalase overexpression has also been shown to reduce various age-related pathological conditions, such as cardiac problems, inflammation-related disorders, and cancer [25].

However, other studies have found that increased antioxidant enzyme activity does not contribute to extended lifespan in rodents [26]. For instance, a study of transgenic mice overexpressing $\mathrm{Cu} / \mathrm{Zn} \mathrm{SOD}, \mathrm{Mn}-\mathrm{SOD}$, and catalase, either alone or in combination, showed that overexpression of these enzymes did not significantly improve longevity compared with wild-type (WT) mice [27].

Glutathione peroxidase 1 (GPX1), the main isoform of the GPX protein family, is an important antioxidant enzyme that is ubiquitous in cells and plays an important role in the neutralization of hydrogen peroxides. While GPX1 expression has a protective effect against ROS-mediated cellular damage, Gpx1-knockout mice showed no evidence of increased oxidative damage to proteins and lipids, compared with their WT littermates [28]. By contrast, mice lacking both Mn-SOD and Gpx1 had a higher level of oxidative DNA and protein damage, but their lifespan was not reduced compared with WT littermates [29]. Moreover, singlenucleotide polymorphisms of Mn-SOD and Gpxlgenes have been shown to impact aging and longevity [30].

Another GPX family protein, GPX4, plays a major role in protecting the plasma membrane from peroxide-induced lipid damage. Null mutations of the Gpx4 gene are lethal in mice. Ablation of GPX4 in a transgenic mice line (C57BL/6 background) resulted in increased oxidative damage in the brain as well as neuronal loss compared with WT mice [31]. Transgenic overexpression of GPX4 was shown to protect mice from the lethal null-mutation phenotype and prevented oxidative-stress-induced liver damage and cell death [32]. However, mice with reduced GPX4 expression and activity showed no significant differences in mean, median, and maximal lifespan compared with WT mice [33]. 


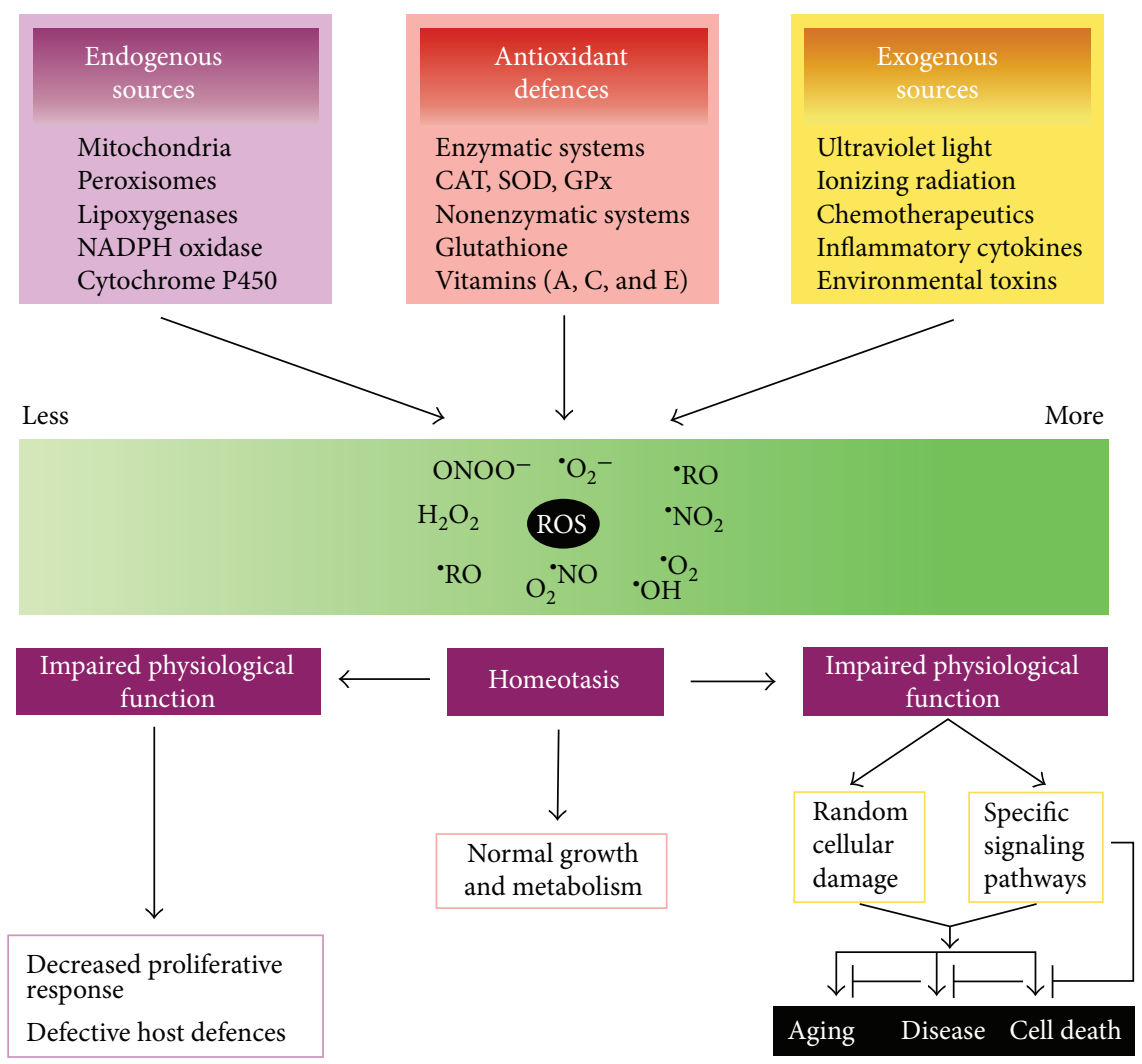

FIgURE 1: The sources and cellular responses to reactive oxygen species (ROS). Oxidants are generated as a result of normal intracellular metabolism in mitochondria and peroxisomes, as well as from a variety of cytosolic enzyme systems. In addition, a number of external agents can trigger ROS production. A sophisticated enzymatic and nonenzymatic antioxidant defense system including catalase (CAT), superoxide dismutase (SOD), and glutathione peroxidase (GPx) counteracts and regulates overall ROS levels to maintain physiological homeostasis. Lowering ROS levels below the homeostatic set point may interrupt the physiological role of oxidants in cellular proliferation and host defense. Similarly, increased ROS may also be detrimental and lead to cell death or to an acceleration in aging and age-related diseases. Traditionally, the impairment caused by increased ROS is thought to result from random damage to proteins, lipids, and DNA. In addition to these effects, a rise in ROS levels may also constitute a stress signal that activates specific redox-sensitive signaling pathways. Once activated, these diverse signaling pathways may have either damaging or potentially protective functions. Reproduced with permission from T. Finkel and N.J. Holbrook: Oxidants, oxidative stress and the biology of aging. Nature, vol. 408, no. 6809, pp.239-247, 2000.

Thioredoxin (Trx) is a redox protein that acts as a hydrogen donor in many reductive reactions in cells. It has two forms: cytoplasmic (Trx1) and mitochondrial (Trx2). Similar to Gpx4, Trx2 null mutations are lethal in mice [34], and $\operatorname{Tr} \times 2$ knockout impairs mitochondrial function by decreasing ATP production; increasing ROS production; inducing oxidative DNA, protein, and lipid damage in the liver; and increasing oxidative-stress-induced apoptosis of liver cells [35]. Trx1 overexpression $\left(\operatorname{Tg}(\operatorname{TRX} 1)^{+/ 0}\right)$ has been shown to protect against oxidative damage of cellular macromolecules and extend the earlier part of the lifespan in male mice; however, neither male nor female $\operatorname{Tg}(\operatorname{TRX} 1)^{+/ 0}$ mice showed changes in maximum lifespan [36].

The cellular location of ROS production may determine whether ROS play a beneficial or detrimental role. For instance, deletion of mitochondrial sod-2 in C. elegans has been shown to promote longevity, whereas deletion of cytoplasmic sod-1 and sod-5 limits lifespan [37]. ROS produced by mitochondrial respiratory complex I reverse electron transport have been shown to improve lifespan in Drosophila [38]. Moreover, respiration inhibition appears to activate the hypoxia-inducible factor-1 (HIF-1) by elevating ROS levels. This activation has been shown to increase longevity $[17,18]$. Studies in genetically modified mice have shown that a moderately impaired mitochondrial function can result in healthier aging, whereas severely altered mitochondrial homeostasis can be detrimental $[39,40]$. Based on these observations, it is clear that both the level and location of ROS production contribute to determining the role of ROS in regulating longevity [41].

\section{Role of ROS in Nuclear and Mitochondrial DNA Damage}

Nuclear and mitochondrial DNA damage caused by ROS contributes significantly to the aging process. Under normal physiological conditions, a myriad of DNA repair mechanisms work in harmony to keep damage contained. Base excision repair, mismatch repair, nucleotide excision repair, and double-strand-break repair all work rigorously to mend DNA damage induced by ROS, X-rays, UV and ionizing radiation, alkaline agents, replication errors, antitumor 
agents, and various chemical agents [42]. Deficiencies in any of these repair mechanisms can accelerate the onset of aging [43].

The DNA theory of aging, first postulated by Szilard in 1959 [44], correlates the steady accumulation of DNA damage with imbalances in cellular function, ultimately leading to cell and organismal aging. Vilenchik and Knudson [45] calculated that the mammalian genome can sustain as many as 1000 lesions per hour per cell. These lesions include oxidative damage to bases, cross-linkages, and single-/doublestrand breaks. Endogenous ROS usually cause the formation of abasic sites by breaking the glycosidic bonds between nucleotide bases and deoxyribose residues [46, 47]. Environmental agents like UV rays and chemical mutagens cause strand breaks through base modifications and intercalations $[48,49]$. When unrepaired damage accumulates, it triggers the DNA damage response (DDR) [50,51], which activates DNA repair systems [43]. Despite the number of lesions from which the genome suffers, the frequency of actual mutations is much lower, precisely because of these well-coordinated sensing and repair systems. However, when DNA repair mechanisms are overwhelmed or become dysfunctional, the DDR triggers senescence or apoptosis to suspend or eliminate the damaged cells, respectively. The accumulation of senescent cells in aging tissues [32] has been implicated as the driving force in the aging process, primarily through inflammatory pathways [33].

DNA repair can be divided into three types: base excision repair (BER), nucleotide excision repair (NER), and nonhomologous end joining (NHEJ). These processes have been reviewed exhaustively in the literature [52-54]. BER typically repairs oxidative DNA damage, most commonly the 8oxoguanine lesion [55]. Briefly, DNA glycosylases excise the damaged base and a polymerase inserts the correct nucleotide in its place [56]. NER corrects more complex lesions not associated with oxidative damage, such as adduct formation between bases and UV-ray-induced cross-linkages [57]. While excision repairs primarily occur during replication, NHEJ can repair DNA double-strand breaks during the resting state as well [58]. NHEJ is a 3-step process that starts with the binding of the broken strand end to the $\mathrm{Ku}$ protein. The damaged and/or mismatched nucleotides are then removed, and the correct sequence is synthesized by DNA polymerase [59].

Unsurprisingly, studies have observed an age-related decline in DNA repair protein levels and activities [55]. Reduced BER activity has been reported in different tissues in older humans [60] and in mice lacking sirtuin 6, a histone deacetylase that is active during DNA repair [61]. Decreased levels of Ku protein and other NHEJ mediators are seen during normal human aging and in cases of Alzheimer's disease [62]. Similarly, NHEJ activity also decreases in aged rats that have accumulated DNA strand breaks in their neurons [63].

The strongest evidence for the DNA theory of aging comes from human progeroid (i.e., premature aging) syndromes, such as Werner syndrome (WS), Bloom's syndrome (BS), and xeroderma pigmentosum (XP). These syndromes are caused by genomic instability and an underlying defect in DNA repair. WS and BS are caused by loss-of-function mutations in the $W R N$ and $B L M$ genes, respectively $[64,65]$. These genes encode RecQ helicases, which are involved in both DNA replication and repair and are known to interact with the Ku protein [66, 67]. Murine knockouts of WRN and BLM have significant genomic instability and impaired DNA repair mechanisms compared with WT mice $[68,69]$. XP is characterized by a mutation in the excision repair cross-complementation group 1 xeroderma pigmentosum group F (ERCC1-XPF) nuclease, which plays an important role in both NER and NHEJ repairs [70]. Mice lacking ERCC1 show accelerated skin aging and increased DNA damage and cellular senescence compared with WT mice [71]. Replicative telomere shortening has been implicated in aging based on studies in the telomerase-knockout mouse model. This mouse model exhibits progeria and accumulates extensive DNA damage (reviewed by [72]). Telomere shortening also accompanies human progeria syndromes, such as WS and BS. More recent studies have directly linked defective DNA repair-specifically BER and NER-to the sites of telomere-uncapping-induced DDR [73, 74]. Examples of specific DNA damage repair and response defects that lead to genetic disorders in humans are shown in Figure 2. Thus, there is substantial evidence linking impaired DNA repair with aging syndromes; however, further studies are needed to provide a direct mechanistic link.

Since mitochondria are the main sites of ROS production, mitochondrial DNA (mtDNA) contains higher levels of oxidative damage and its mutation rate is significantly greater than that of the nuclear DNA [75]. In addition to their proximity to the sites of ROS generation, it is likely that the mitochondrial genomes are more prone to oxidative damage because histones and other chromatin-associated proteins, present in nuclear genomes where they act as scavengers of oxygen radicals, are absent in the mitochondria. The existence of repair of oxidative damage to mtDNA, originally reported in the early '90s, is well established [76-78]. BER appears to be the only excision repair process active in the mitochondrial genomes. All mtDNA repair proteins are encoded by the nuclear genome and imported into the mitochondrial matrix. Most mtDNA repair proteins discovered so far are isoforms of the nuclear BER proteins arising from differential splicing or truncation of the terminal sequences $[79,80]$. The mitochondrial DNA polymerase $\gamma(\operatorname{Pol} \gamma)$ and mtDNA ligase (Lig III $\alpha$ ), involved in mtDNA replication, appear to also be functional in mitochondrial $\operatorname{BER}[79,80]$.

Accumulation of somatic mtDNA mutations has been found to accelerate normal aging [81-84], leading to oxidative damage, energy failure, increased production of ROS, and accumulation of amyloid-beta peptide (Abeta) [85, 86], a key molecule in Alzheimer disease (AD) [83]. A vicious cycle ensues which reinforces mtDNA damage, the impairment of the mitochondrial respiration, and oxidative stress.

\section{Role of ROS in Protein Homeostasis}

Similar to DNA damage, age-related protein damage and the accumulation of damaged protein products contribute to aging. Therefore, it is critical to understand how ROS 


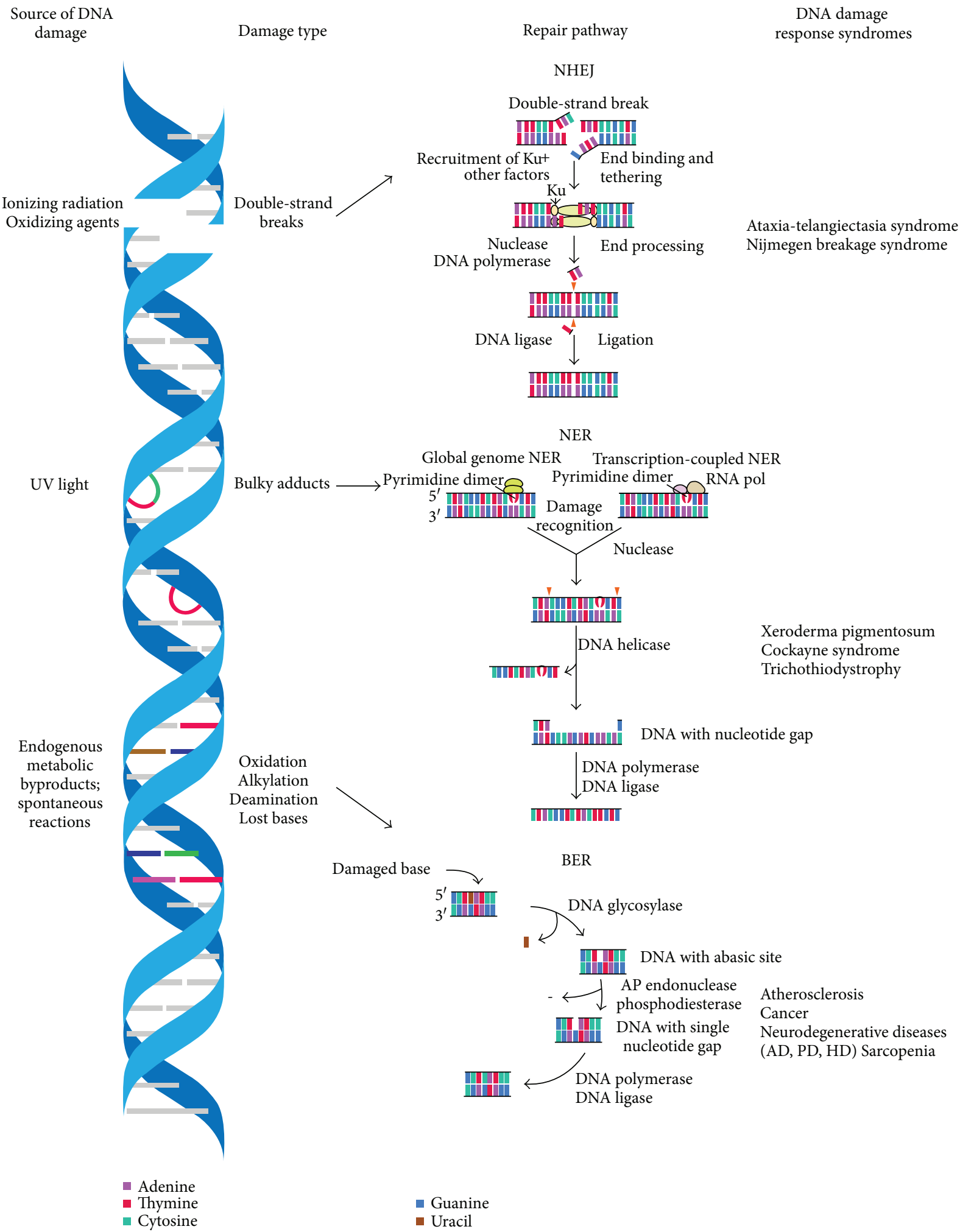

FiguRE 2: Examples of distinct DNA damage repair and response defects leading to genetic disorders in humans. Various damage types, including DNA double-strand breaks, bulky lesions, and base lesions, require nonhomologous end joining (NHEJ), nucleotide excision repair (NER), and base excision repair (BER), respectively. Defects in DNA-damage-response pathways lead to genome instability and, consequently, to complex syndromes characterized by tissue degeneration, cancer susceptibility, developmental defects, and premature aging. AD: Alzheimer's disease; PD: Parkinson's disease; HD: Huntington's disease. 
contribute to an imbalance in cellular protein homeostasis and alter the aging process.

Free radicals can "attack" proteins, causing oxidative damage. Oxidative damage can alter protein function. Further, it can produce carbon-oxygen double bonds at arginine, lysine, proline, and threonine side chains, forming reactive ketones or aldehydes, known as protein carbonyls [87], normally considered to reflect the overall levels of cellular oxidative stress [88]. Protein carbonyls are associated with the production of aberrant protein isoforms $[89,90]$. Unlike other oxidative modifications, such as disulfide bond formation, protein carbonylation is irreversible. Thus, the only means of limiting the damage caused by the affected proteins is their degradation. As more oxidative damage accumulates, proteins are more likely to misfold. Moderately oxidized proteins undergo degradation by the proteasome, the highly sophisticated protease complex designed to carry out selective, efficient, and processive degradation of short-lived, damaged, misfolded, or otherwise obsolete proteins [53]. However, heavily oxidized proteins can crosslink with other proteins, which prevents their degradation [54]. As a consequence, heavily damaged proteins accumulate within the cell, affecting its proper functioning. Accordingly, impaired proteostasis is a hallmark of many age-related diseases, including Alzheimer's and Parkinson's disease $[91,92]$.

Many studies have shown links between protein homeostasis, ROS, and oxidative stress. For instance, reducing insulin/IGF-1 signaling or inhibiting downstream mTOR signaling has been shown to improve the homeostasis of Alzheimer's disease-associated proteins, promoting longevity and protecting cognitive function in animal models [93]. Several studies in C. elegans have also shown that the heat shock factor 1 (HSF-1) works with the FOXO-like transcription factor, daf-16, to improve protein homeostasis and increase lifespan $[94,95]$. Treating $C$. elegans with the amyloid-binding dye thioflavin $\mathrm{T}$ has been shown to reduce protein aggregation and extend lifespan via HSF-1- and SKN-1-/Nrf-mediated signaling [96]. Another study comparing the role of small heat shock proteins in Drosophila identified two proteins-CG14207 and HSP67BC-involved in proteostasis which mildly improved longevity when overexpressed in Drosophila [97].

Two important proteolytic pathways are the ubiquitinproteasome pathway (UPP) and autophagy [98]. The UPP is a proteolytic system responsible for the majority of intracellular protein degradation. A key aspect of UPP-mediated proteolysis is the selective targeting of proteins for degradation via posttranslational modifications, particularly ubiquitination and sumoylation [77, 78]. Aging is associated with increased levels of ubiquitinated and sumoylated protein in various tissues [99-103], potentially as a result of agedependent UPP malfunctioning $[104,105]$.

Ubiquitination pathways have been shown to play a significant role in regulating lifespan [106, 107]. In Drosophila, a loss-of-function mutation in the ubiquitin-activating enzyme Ubal significantly reduced lifespan and weakened motor function [108]. In C. elegans, overexpression of the E3 ubiquitin ligase, WWP-1, increased lifespan via signaling mediated by the forkhead box A (FoxA) transcription factor [109].

Enhanced expression of the proteasome assembly protein Ump1 has also been associated with enhanced viability following exposure to various oxidative stress factors (e.g., menadione, hydrogen peroxide, and 4-hydroxynonenal) in S. cerevisiae [89]. This increased viability was associated with an enhanced preservation of proteasome-mediated protein degradation. Interestingly, cells expressing elevated levels of Ump1 also exhibited an enhanced preservation of proteasome-mediated protein degradation and enhanced viability during stationary-phase aging. Taken together, these data strongly support a key role of the proteasome during oxidative stress and aging [89].

Autophagy is also essential for maintaining protein homeostasis, as both cellular autophagy and mitophagy (autophagy of an entire mitochondrion) impact lifespan $[90,110]$. Three autophagy proteins (LC3B, ATG5, and ATG12) play an important role in preserving mitochondrial integrity and lifespan [111]. In human umbilical vein endothelial cells, targeted mitochondrial damage was found to initiate a cascade of events involving a short-term increase in ROS production, followed by mitochondrial fragmentation and upregulation of LC3B, ATG5, and ATG12. This cascade significantly enhanced the replicative lifespan up to $150 \%$ and the number of population doublings up to $200 \%$ [111]. Additionally, in normal aging and during the progression of age-related pathologies, autophagy is responsible for the removal of proteins damaged by oxidation, for instance, from the brain to restore its proper function $[112,113]$.

During aging, mitochondria-the primary source of ROS-are often subjected to oxidative damage at a level that supersedes the protective capacity of the antioxidant response. In such cases, removal of damaged mitochondria through mitophagy is crucial to mitigate the detrimental effects on the organism [114]. Furthermore, in C. elegans, tight coupling between mitophagy and mitochondrial biogenesis is important for promoting longevity under stress conditions [115]. Also, in flies, overexpression of the mitophagy protein PARKIN has been shown to extend lifespan by enhancing mitochondrial turnover [116]. Therefore, mitophagy acts as a major marker of ROS-induced damage and plays a significant role in aging and various age-related disorders [117].

\section{The Nucleus-Mitochondria Connection and the Importance of Mitochondrial Proteostasis}

Nuclear DNA damage induces nuclear-to-mitochondrial signaling (NM signaling). This process plays a vital role in mitochondrial homeostasis and aging. Nuclear proteins (e.g., HIF-1 $\alpha$, proliferator-activated receptor gamma coactivator-1 $\alpha$ (PGC-1 $\alpha$ ), forkhead box protein $\mathrm{O}(\mathrm{FOXO})$, and the sirtuin family) together with nuclear DNA damage repair proteins can affect mitochondrial integrity and contribute to age-related pathologies [118]. Recent studies have established an important connection between nicotinamide adenine 


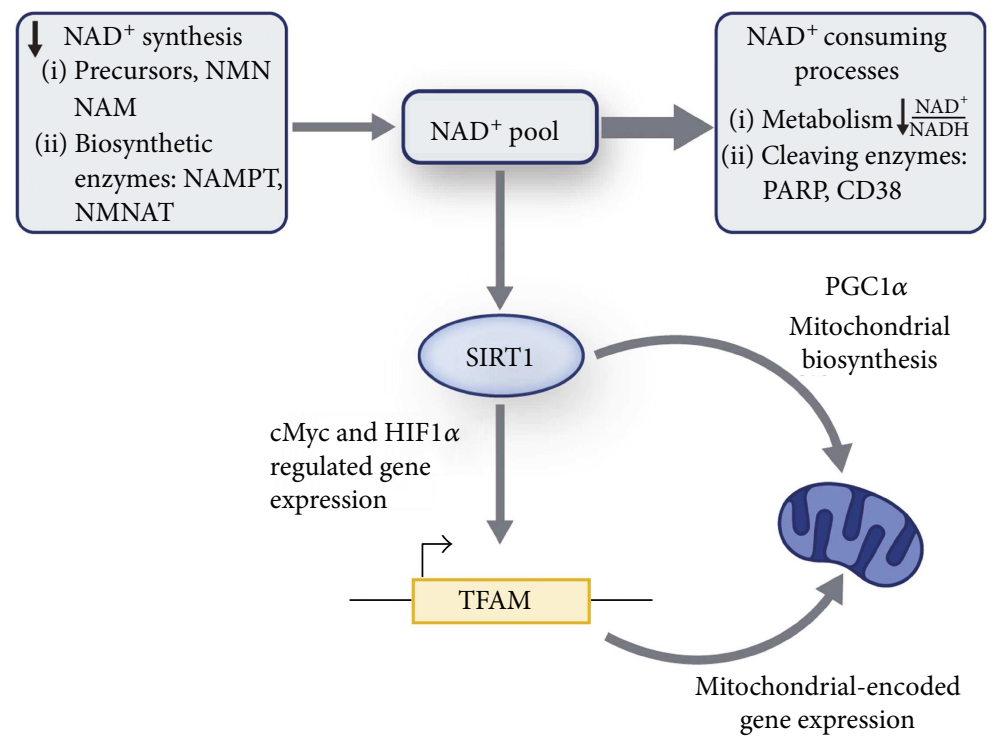

FIgURe 3: Age-dependent decline in $\mathrm{NAD}^{+}$. Decreased $\mathrm{NAD}^{+}$synthesis and increased $\mathrm{NAD}^{+}$consumption with age may both contribute to a decrease in the $\mathrm{NAD}^{+}$pool. A reduction in $\mathrm{NAD}^{+}$levels leads to an age-related reduction of SIRT1 activity. Reduced SIRT1 activity impacts mitochondrial function through at least two mechanisms: (1) a reduction in biogenesis secondary due to a reduction in PGC1- $\alpha$ activity and (2) an impairment of mitochondrial function due to a reduction in mtDNA replication and transcription. Reproduced with permission from Prolla, T.A. and Denu, J.M., 2014. NAD+ deficiency in age-related mitochondrial dysfunction. Cell Metabolism, 19(2), pp.178-180.

dinucleotide $\left(\mathrm{NAD}^{+}\right)$and DNA repair proteins in maintaining mitochondrial metabolism and increasing lifespan [119].

Sirtuins, $\mathrm{NAD}^{+}$-dependent deacetylases, act as metabolic sensors that perceive imbalances in the $\mathrm{NAD}^{+} / \mathrm{NADH}$ ratio. The inhibition of DNA repair proteins, specifically $\mathrm{NAD}^{+}$consuming poly (ADP-ribose) polymerase proteins (PARP1 and PARP-2), increases cellular $\mathrm{NAD}^{+}$levels [119]. High $\mathrm{NAD}^{+}$levels subsequently activate sirtuins, which in turn promote higher mitochondrial content, increased energy expenditure, and protection against metabolic disease [119], ultimately extending longevity [120]. Furthermore, sirtuin activators, such as resveratrol, have been shown to promote longevity $[121,122]$ by inducing calorie restriction- (CR-) like effects in C. elegans [123].

However, both PARP and sirtuins must consume $\mathrm{NAD}^{+}$ to be functional. Large amounts of PARP and sirtuins can deplete cellular $\mathrm{NAD}^{+}$levels. Depleted $\mathrm{NAD}^{+}$levels lead to sirtuin inactivation and excessive ROS production, which alters mitochondrial integrity [124]. Moreover, perturbations in the activity of sirtuins deactivate several enzymes including PGC- $1 \alpha$ (peroxisome proliferator-activated receptor gamma coactivator $1 \alpha$ ), forkhead box $\mathrm{O}$ (FOXO) transcription factors, hypoxia-inducible factor- $1 \alpha$ (HIF- $1 \alpha$ ), and AMP-activated protein kinase (AMPK), which modulates the production of various antioxidative enzymes, affecting oxidative defense mechanisms [125].

DNA-damage-induced NM signaling through the PARP-NAD ${ }^{+}$-sirtuin axis can accelerate the onset of aging by disrupting mitochondrial integrity. Thus, genetic or pharmacological interventions targeting proteins or metabolites involved in NM signaling can potentially promote longevity. For instance, in aging rats, treatment with the PARP inhibitor INO-1001 reduces cardiovascular disorders [126], and treatment with the PARP inhibitor PJ34 improves myocardial contractile function and restores endothelial function [127]. Furthermore, PARP-1 inhibition may protect against age-dependent endothelial dysfunction, potentially by regulating NO bioavailability via iNOS [128].

However, the beneficial role of PARP-1 inhibition in aging has been questioned [129]. For instance, PARP-1-null mice have a reduced lifespan, an earlier onset of aging, and an increased rate of spontaneous carcinogenesis compared with WT mice [130]. One explanation for discrepancies among studies is the dual role of PARP: while PARP contributes to maintain genomic stability and promote longevity, excessive PARP activity depletes cellular $\mathrm{NAD}^{+}$and triggers nuclear factor- $\kappa \mathrm{B}-(\mathrm{NF}-\kappa \mathrm{B}-)$ induced inflammation, leading to the rapid onset of aging and age-related disorders [131].

Aging is accompanied by decreased $\mathrm{NAD}^{+}$synthesis and increased $\mathrm{NAD}^{+}$consumption, resulting in a net decrease in the pool of available $\mathrm{NAD}^{+}$(Figure 3). Reduced NAD levels lead to an age-related reduction of sirtuin 1 (SIRT1) activity. Reduced SIRT1 activity impacts mitochondrial function through at least two mechanisms: (1) reduced biogenesis secondary to a reduction in PGC1- $\alpha$ activity and (2) impaired mitochondrial function due to a reduction in mitochondrial DNA replication and transcription $[132,133]$. Therefore, supplementation with $\mathrm{NAD}^{+}$or its precursors is hypothesized to promote healthy aging and longevity [134-136].

Experimental models have shown that $\mathrm{NAD}^{+}$supplementation is beneficial for maintaining carbohydrate metabolism, cardiovascular function, stem cell function, and longevity [137]. Moreover, nicotinamide prevents cellular senescence by reducing excessive ROS production [138, 139]. Several human clinical studies testing the efficacy of this compound are ongoing [140].

The $\mathrm{NAD}^{+}$-mediated improvement in C. elegans lifespan was shown to involve a series of interconnected mechanisms 
that include (1) activation of the worm sirtuin homolog Sir-2.1, (2) nuclear translocation and activation of the FOXO transcription factor daf-16, and (3) increased expression of antioxidative enzymes [141].

In a mouse model, treatment with the $\mathrm{NAD}^{+}$precursor nicotinamide riboside (NR) delayed muscle and neural stem cell senescence and increased longevity. This effect seemed to be mediated by the induction of the mitochondrial unfolded protein response (UPRmt) [142]. Involvement of the UPRmt in the lifespan-extending effect of $\mathrm{NAD}^{+}$has also been proposed in C. elegans [143].

The UPRmt is a form of retrograde signaling that contributes to ensuring the maintenance and functional integrity of the mitochondrial proteome [144]. Accumulation of misfolded proteins or unassembled complexes in the mitochondria beyond a certain threshold leads to altered proteostasis that can result in organelle/cell dysfunction [145]. Mitochondria relay this distress message to the cytosol and nucleus through various types of signals, and in response, the cell elicits a set of responses, including the production of mitochondrial localized molecular chaperones and proteases to promote the recovery of organellar protein homeostasis [91, 92, 146, 147].

An adaptive pathway triggered by a sirtuin-dependent UPRmt, which results in increased mitochondrial complex content and activity $[143,148]$, has been shown to lead to increased lifespan, at least in mice and flies [143, 142, 146]. Mitochondrial retrograde signaling to the nucleus via the mTOR pathway has also been found to extend normal human fibroblast lifespan, increase the mitochondrial membrane potential, reduce ROS level, and enhance autophagic flux [149]. ROS can exert an additional burden on the protein quality control system since protein chaperones themselves are susceptible to oxidative damage resulting in further damage accumulation and accelerated aging $[4,65]$.

Collectively, these studies establish a ROS-mediated connection between the mitochondria, the nucleus, and proteostasis.

\section{Role of ROS in Nonpharmacological Strategies to Extend Lifespan}

6.1. Calorie Restriction (CR). The term "caloric restriction" designates reduced energy intake without malnutrition, and it represents the most effective and reproducible dietary intervention known to promote healthy aging and slow down the manifestation of age-related disorders in various model organisms including yeast [150-153], nematodes [154, 155], fruit flies [156], mice [157-159], and primates [160]. CR regulates numerous physiological processes associated with aging, including metabolism [161-165], oxidative stress [166, 167], genomic stability [168], and growth signals [169-171].

Four major theories have been proposed to account for the beneficial effects of caloric restriction. According to the "oxidative damage attenuation" hypothesis, oxidative damage is decreased during caloric restriction (CR), through the decreased production of reactive oxygen species and the upregulation of protective enzymes, resulting in a decrease in DNA damage and increase in genomic stability [168, 172, 173]. The "glucose-insulin" hypothesis suggests that the decreased levels of circulating insulin and glucose that accompany CR lead to decreased cell growth and division, shifting the resources of the cell towards maintenance and repair [172, 173]. The related "insulin-like growth factor (IGF) 1" hypothesis suggests that decreased levels of growth hormone and IGF-1 in response to CR promote maintenance and repair activities [172, 173]. Finally, the "stress-adaptation" (or hormesis) hypothesis suggests that CR promotes a low level of stress which induces crossadaptation to other stress factors by increasing the levels of antioxidant and DNA repair proteins [174].

Several molecular explanations for the lifespanextending effects of CR have been proposed. However, much is still unknown about the precise contribution of each pathway to the lifespan-extension effect of CR. This understanding is further complicated by the extensive crosstalk between the different pathways and by the fact that some pathways are present in some model organisms but not in others. The complex network of pathways that are involved in the lifespan-extending effects of caloric restriction is depicted in Figure 4.

Two of the most studied pathways purportedly involved in the lifespan-mediated extension conferred by CR are those mediated by inhibition of insulin/IGF-1 signaling and inactivation of mTOR (mechanistic target of rapamycin). Both are considered nutrient-sensing pathways (insulin for glucose and mTOR for amino acids). Decreases in circulating levels of nutrients (amino acids, glucose, and even cholesterol) - all of which are also sensed by mTOR - contribute to decreased mTOR activity during CR [175]. mTOR inhibition leads to SKN-1-/Nrf- and daf-16-/FOXO-mediated activation of protective genes, resulting in an increase in stress resistance and longevity [176]. Additionally, inhibition of mTOR is known to induce autophagy, which has an important role in proteostasis during aging $[177,178]$. The lifespan-extending effect of mTOR inhibition, either genetically or chemically, seems to be very conserved across different model organisms [159, 179-181]. The insulin pathway is mediated via several additional enzymes including PI3K/Akt/Ras and the forkhead O (FOXO) transcriptional factor [182-184].

The pathway mediated by adenosine monophosphateactivated protein kinase (AMPK) is a third possible CRrelevant pathway that can, in some organisms, crosstalk with the mTOR pathway. AMPK is a highly conserved sensor of increased levels of AMP and ADP originating from ATP depletion [185-187]. In general, activation of AMPK acts to maintain cellular energy stores, switching on catabolic pathways that produce ATP, mostly by enhancing oxidative metabolism and mitochondrial biogenesis, while switching off anabolic pathways that consume ATP. The importance of AMPK in determining lifespan is demonstrated by the fact that treatment with metformin, an AMPK activator, extends the lifespan of C. elegans and short-lived, cancer-prone mice strains [188-190].

One additional important pathway is that directed by sirtuins, the activity of which increases with CR. Association of sirtuins with decreased oxidative stress levels and increased 


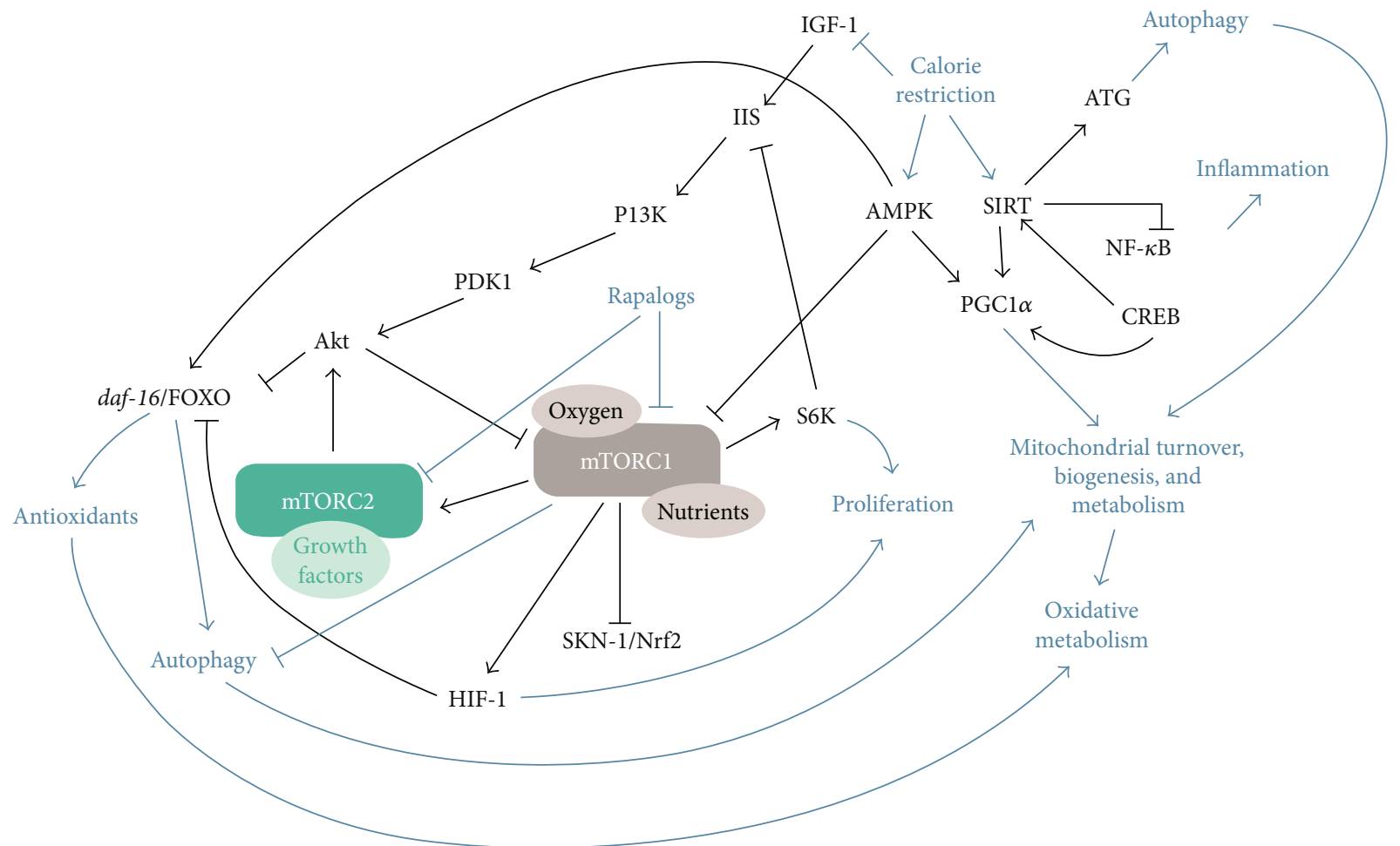

FIGURE 4: Crosstalk between mTOR and other longevity pathways. mTORC1 responds to a variety of environmental cues, including oxygen and nutrients, and communicates with several other known longevity factors in a complex network of interactions. Rapalogs inhibit mTORC and decrease its activity. Sensing of low oxygen levels stimulates mTORC1 to activate the hypoxic response by enhancing translation of HIF-1, which inhibits FOXO family members and increases longevity. mTORC1 inhibits the stress response transcription factor SKN-1/Nfr2, resulting in extended lifespan. Inhibition of the mTOR downstream effector ribosomal protein S6 kinase (S6K), involved in the regulation of protein translation, also results in extended lifespan. Caloric restriction can lower mTORC1 signaling partly through activation of AMPK, resulting in enhanced longevity, potentially via PGC1 $\alpha$-mediated increase in mitochondrial metabolism. Calorie restriction also inhibits IGF1-dependent signaling via PI3K/PDK1/Akt which inhibits FOXO, blocking the expression of antioxidants and autophagy. Calorie restriction leads to increased $\mathrm{NAD}^{+} / \mathrm{NADH}$ ratio, which activates sirtuins, that in turn induce mechanisms to enhance cell protection, including enhanced antioxidant production and autophagy. Calorie restriction can also block inflammation via the effects of sirtuins on NF- $\kappa$ B. cAMP response element binding proteins (CREB) can also upregulate the transcription of sirtuins, slowing aging.

antioxidative defense has been proposed for several model organisms [191, 192], as well as humans, but the exact molecular mechanisms behind this association remain unclear. SIRT3 has been suggested as an essential player in enhancing the mitochondrial glutathione antioxidant defense system during caloric restriction [193]. SIRT3-dependent mitochondrial adaptation may also contribute to delaying aging in mammals [193].

Their role as mediators in the beneficial effects exerted by caloric restriction have made sirtuins promising pharmacological targets to delay aging and age-related diseases [194]. Resveratrol is a polyphenol antioxidant found in red wine and shown to activate sirtuins in several organisms, including humans [195, 196]. Resveratrol is also an AMPK activator, and this activity can also contribute to the beneficial effects of this polyphenol [197]. Purportedly, resveratrol upregulates antioxidant defense mechanisms and attenuates mitochondrial ROS production via sirtuin activation. Significant reduction of cellular hydrogen peroxide [198-200], upregulated MnSOD expression [195, 196], and increased cellular glutathione content [201] have been observed after resveratrol administration. The therapeutic potential of resveratrol has been the subject of intense research over the last decade (e.g., [195-198]).

$\mathrm{CR}$ has also been shown to reduce age-related accumulation of oxidative damage by decreasing mitochondrial respiration, membrane potential, and the rate of ROS production $[166,167]$, although CR seems to have only a minor effect on age-related changes in the mitochondrial proteome [202]. CR also increases mitochondrial biogenesis through the PGC- $1 \alpha$ signaling pathway [203]. Moreover, other studies have also shown that CR protects from age-related vascular malfunctioning by increasing nitric oxide (NO) bioavailability, reducing ROS production, triggering antiinflammatory responses, and preventing oxidative damage by activating the NRF-antioxidant response element (ARE) signaling pathway $[204,205]$.

Caloric restriction typically involves a $20-40 \%$ reduction of food consumption relative to normal intake. This is a rather severe intervention that can have detrimental effects [191]. Intermittent or periodic dietary restrictions without chronic caloric restriction have the potential to provide a significant health span increase while minimizing adverse effects. In fact, studies in rodents have shown that even a 
$10 \%$ decrease in food consumption can substantially affect lifespan [206]. Sod ${ }^{-1-}$ mice show increased levels of oxidative stress, which in turn results in reduced lifespan. Dietary restriction ( $60 \%$ of ad libitum fed diet) was shown to increase the lifespan of $\mathrm{Sod}^{-1-}$ mice by $30 \%$, making it similar to that of wild-type, control mice fed ad libitum [207], by reducing lipid peroxidation in the liver and brain. The same dietary intervention was found to attenuate age-associated muscle atrophy by lowering oxidative stress in mice even in complete absence of the key antioxidant enzyme CuZnSOD [208].

6.2. Exercise. Exercise is another effective nonpharmacological means of delaying the negative effects of aging. Several studies reported elevated $\mathrm{O}_{2}$ load in skeletal muscle fibers $[209,210]$ and increased ROS levels $[209,211]$ during exercise as a result of increased mitochondrial respiration required to generate ATP for muscle contractions. While mitochondrial oxidative phosphorylation is the primary source of exercise-induced ROS, xanthine oxidase and endothelial nitric oxide synthase (eNOS) also contribute to ROS generation during endurance training [212] and stretching exercises [40, 41]. Regular exercise has been associated with lowered mortality and incidence of age-related diseases [213-215]. Therefore, exercise interventions potentially could have benefits for older individuals through modulation of inflammatory and redox status, which can influence proteostasis, insulin sensitivity, body composition (e.g., adipose tissue), and hormone levels [216].

An aging-associated increase in ROS production in skeletal and cardiac muscle cells during rest and in a postexercise state has been reported [211, 217]. At the muscular level, age-related increases in ROS levels have been associated with various mechanisms, such as ETC dysregulation due to decreased activity of cytochrome $c$ oxidase and other enzymes [218] and mitochondrial membrane disruption due to lipid peroxidation and unsaturation [44, 45].

However, conflicting results also have been reported. A study of the skeletal and cardiac muscle tissues of aged rats showed a significant increase in antioxidant enzymes, such as SOD, catalase, GPX [47-50], and glutathione (GSH) [51, 132]. Additionally, muscles that undergo chronic exercise show lower oxidative stress in terms of lipid, protein, and DNA damage in both humans and model organisms [38, 49, 133]. Accordingly, mitochondria isolated from trained muscle cells showed higher oxidative resistance in vitro [55, 219]. Studies also show an increase in SOD, GPX, and GSH levels following endurance training in both young and old individuals $[56,57]$. These results suggest that regular physical exercise is accompanied by an adaptation of the cells to deal with oxidative stress, which in turn elicits beneficial effects, for example, in the immune system [220]. This idea is summarized by the concept of hormesis. Hormesis can be defined as the adaptive response seen in organisms continuously exposed to low to moderate levels of stress. Under these conditions, cells develop an adaptive response, including increased expression of antioxidant genes, which in turn makes them resistant to multiple stressors [221, 222].

The induction of hormesis is controlled by redox sensor pathways which, upon activation by oxidants, upregulate the antioxidant enzymatic system [223]. For example, intense physical exercise activates the mitogen-activated protein kinase (MAPK) and the NF- $\kappa \mathrm{B}$ redox signaling pathways in both humans and rodents $[60,61]$. The major targets of these pathways are antioxidant enzymes, including SOD, GPX, and GSH which contain NF- $\kappa$ B and activator protein-1 (AP-1) binding sites in their promoters [62-65] as well as responsive elements to various stimuli like proinflammatory cytokines, oxygen tension, and ROS [66-68]. In skeletal muscles, another crucial hormetic adaptation to oxidative stress is the increase in mitochondrial mass and protein content $[69,70]$, particularly the level of cytochrome c oxidase. Cytochrome coxidase controls electron flow and the superoxide formation in the ETC [224]. These changes upregulate the expression of PGC-1, which drives mitochondrial biogenesis in skeletal muscles during exercise [225]. PGC-1 is also linked with reduced oxidative stress [226].

It has been hypothesized that this hormetic response to oxidative stress becomes impaired as skeletal muscles age $[218,227]$. This hypothesis is supported by several studies reporting significantly lower NF- $\kappa \mathrm{B}$ expression and activity in aged muscles [217, 228, 229]. By contrast, other studies have reported unchanged [230] or even higher [231] NF- $\kappa \mathrm{B}$ levels at a resting state and decreased MAPK pathway activation postexercise in aged muscles of rodents and humans.

While exercise interventions have been proposed as effective, nonpharmacological means of delaying the negative effects of aging on functional and metabolic parameters [216], it is also well known that regular vigorous exercise can have detrimental effects, as evidenced by the enhanced susceptibility of elite athletes to infections [232]. This effect seems to be at least partly due to the detrimental effects of long-term exposure to the enhanced ROS production associated with intense exercise practice. For instance, chronic muscle injury, a common affliction of not only athletes but also older individuals, increases the production of proinflammatory cytokines, such as tumor necrosis factor- $\alpha$ (TNF- $\alpha$ ) and interleukin-6 (IL-6), which further contribute to oxidative stress that, in turn, exacerbates muscle inflammation, creating a vicious cycle of inflammation and oxidative damage [233].

Additional studies are needed to resolve the conflicting results regarding the effects of exercise and exerciseinduced hormesis on the oxidative stress status skeletal muscles and its progression throughout the lifespan.

\section{ROS versus Aging: May Bacteria Take the Stand}

Until recently, dogma held that bacteria do not undergo any events that are equivalent to the aging process [234]. However, this viewpoint has changed over the last decade. Bacterial aging was first reported in the asymmetrically dividing Caulobacter crescentus $[235,236]$. In this $\alpha$-Proteobacteria, cell division is both morphologically and functionally asymmetric. This asymmetry produces a clear distinction between mother and daughter cells. Ackermann et al. [162] reported that, over multiple divisions, the time required for a mother cell to yield a new daughter cell doubled from $2.6 \mathrm{~h}$ to $5 \mathrm{~h}$ 
per division cycle, a process similar to replicative aging in eukaryotes [235, 236]. Later, Stewart et al. [237] demonstrated that Escherichia coli also displayed features of replicative aging despite dividing by symmetrical, binary fission. Using automated time-lapse microscopy to image 8-10 reproduction cycles of individual cells, the authors observed that the old-pole (mother) cells showed a decreased growth fitness (e.g., growth rate) over successive generations, compared with their new-pole (sister) cells. The old-pole cells had reduced offspring formation and increased incidence of cell death. After approximately 100 divisions, the old-pole cells ceased to grow [237].

Subsequent research demonstrated that similar processes occur in Bacillus subtilis [238] and Mycobacterium spp. [239] (Figure 5). These observations confirm that aging in bacteria is a more general phenomenon than once thought, which affects not only microbes with distinct morphologies within the mother-to-daughter lineage but also those in which growth asymmetry is seen in the progeny at the functional/ molecular level.

7.1. Aging and Conditional Senescence. During the stationary phase, as a result of nutrient limitation, E. coli cells enter a unique state known as conditional senescence [240]. Once rendered senescent, bacteria continuously lose their culturability and are unable to resume growth even when nutrients become available again. This feature makes conditional senescence very similar to human somatic cell senescence [100-103], and the replicative lifespan of yeast (S. cerevisiae), which is commonly used to model the aging process of mitotic tissues in higher organisms [241].

The observed functional asymmetry in bacterial division, initially reported by Stewart et al. [237], has been associated with asymmetric segregation of damaged cell components (e.g., protein aggregates) [242, 243], a process also present in eukaryotes [244-246]. Asymmetric protein damage aggregation seems to be an active process in yeast [87]. In bacteria, this process seems to be mainly passive and driven by molecular crowding [247].

Batch cultures of E. coli subjected to starvation-induced growth arrest exhibit markedly higher loads of damaged (carbonylated) proteins [248], a feature also present in aging eukaryotes [249, 250]. However, this load does not seem to be uniformly distributed in the population. Interestingly, low-carbonyl-load cells remained reproductively competent, whereas high-carbonyl-load cells were genetically dead (i.e., unable to be cultured). Whether this starvation-induced heterogeneity in carbonylation and fitness is programmed and whether it is the result of damage segregation during cytokinesis has not been elucidated. Bacterial cell senescence induced by other external stimuli, including UVA radiation, is also associated to the accumulation of protein carbonyls as a result of oxidative damage [251-253] (Figure 6).

Time-dependent accumulation of protein carbonyls has been observed during the stationary phase in E. coli [254]. The activities that contribute to protein oxidation during the stationary phase are shown in Figure 7. Given that one of the criteria for aging is an increase in mortality rate over time [255], this time-dependent accumulation of protein carbonyls provides a compelling argument that prokaryotes, such as E. coli, age. Some proteins, such as tricarboxylic acid (TCA) cycle enzymes, seem to be particularly susceptible to carbonylation [256]. Interestingly, cells lacking SOD-1 activity display higher amounts of protein carbonylation and lose viability more rapidly in the stationary phase [248]. Furthermore, stationary-phase populations incubated in the absence of oxygen have significantly extended lifespans compared to counterparts grown in the presence of oxygen [254]. These observations highlight the involvement of ROS and oxidative stress in stationary phase-associated senescence.

During the stationary phase and under stressful conditions, the oxidation of specific proteins in E. coli takes place. These proteins include DnaK (an Hsp70 chaperone), DNA-binding protein $\mathrm{H}-\mathrm{NS}$, universal stress protein A (UspA), the elongation factors EF-Tu and EF-G, glutamine synthetase, glutamate synthase, and aconitase [254, 256, 257]. Interestingly, some of these proteins are also carbonylated in yeast cells under oxidative stress [258], in aging flies [259, 260], and in the human brain of individuals with Alzheimer's disease [261]. These observations suggest that unchecked oxidative damage in the form of protein carbonylation could be the proximal cause of aging among stationary-phase E. coli populations [248]. However, there is no direct proof of this hypothesis.

Growth-arrested, stationary-phase E. coli develop resistance to heat and oxidative stress, a phenomenon known as stasis-induced cross-protection [262]. Cells starved of carbon or nitrogen are markedly more resistant to heat shock and oxidative stress than proliferating cells [262, 263]. An association between stress resistance and lifespan has been described in several eukaryotic model organisms [264-267]. These observations indicate that there might be an evolutionarily conserved mechanism channeling resources away from reproduction and toward maintenance and protective functions [268]. Similar to eukaryotes, the ability of cells to quench ROS may play a role in determining the bacterial lifespan [248].

However, as with eukaryotes, there are conflicting results regarding the contribution of ROS to bacterial senescence. For instance, reproductively arrested populations of $E$. coli have increased levels of oxidative defense proteins and increased population resistance to external oxidative stresses $[138,139]$. However, these populations also display higher levels of damaged proteins [254, 256]. Additionally, no strict correlation has been observed between respiratory activity, protein oxidation, and the lifespan of growth-arrested E. coli [269]. Similar results have been observed in G0-growtharrested yeast cells [270].

The first genes induced following growth arrest in bacteria play roles in countering stasis-induced senescence and death $[262,271]$. Many of these genes encode proteins that protect the cell from external stresses, such as heat, oxidants, and osmotic challenge, which could account for stasisinduced cross-protection [262]. Cross-protection relies on the sigma factor Sigma-S [272]. Under not only starvation but also general stress conditions, the Sigma-S transcription factor accumulates, binds, and directs RNA polymerases toward more than 50 specific genes [272]. E. coli mutants 
Caulobacter crescentus

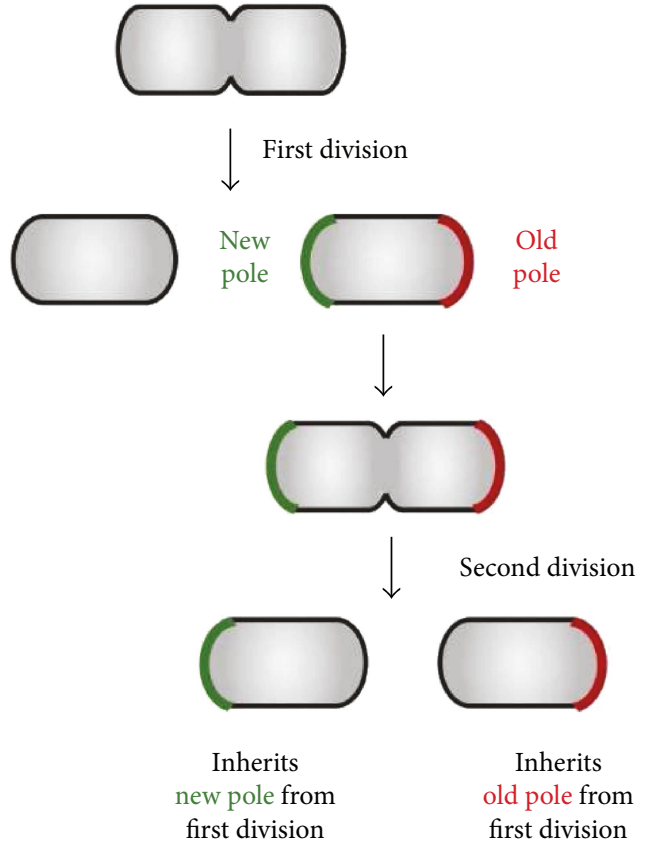

(a)

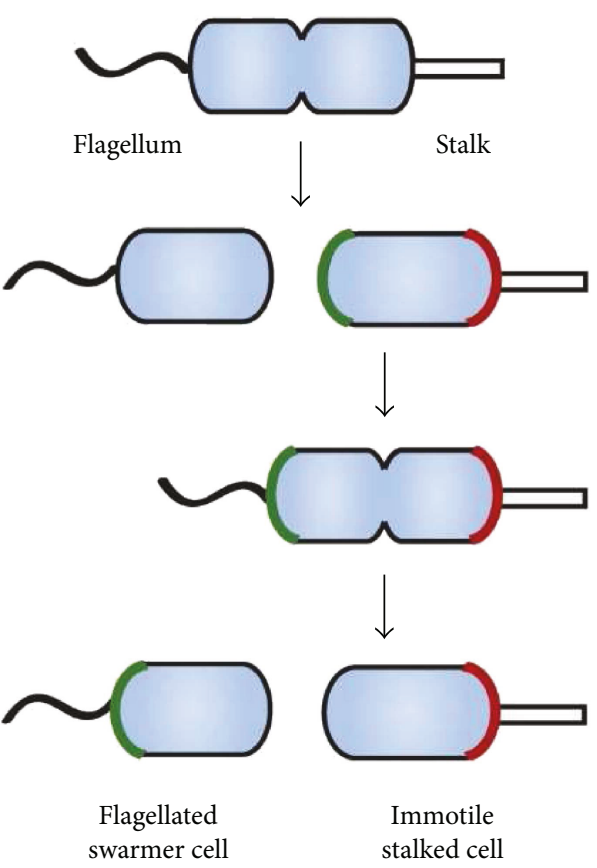

(b)

Mycobacterium

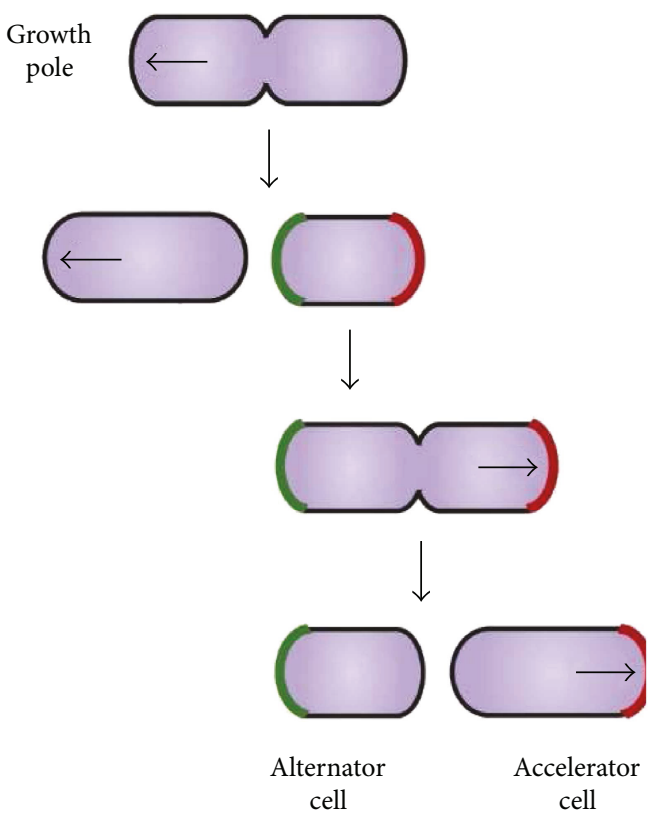

(c)

FIGURE 5: (a) All cell divisions in rod-shaped bacteria are asymmetric in that one daughter cell inherits the "new" pole (green) from a previous division and the other inherits the "old" pole (red). In some bacteria, this asymmetry is used to create functional specialization of daughter cells. (b) In C. crescentus, different polar appendages form at the new and old poles, leading to dimorphic daughter cells. (c) In Mycobacterium, cells preferentially grow at the old pole (marked with an arrow). Daughter cells that inherit the old pole, called accelerators, continue growing whereas those inheriting the new pole, called alternators, must form a new growth pole before elongating. Reproduced with permission from Aakre CD, Laub MT. Asymmetric cell division: a persistent issue? Developmental cell. 2012; 22 (2):235-236. doi:10.1016/j.devcel.2012.01.016. 


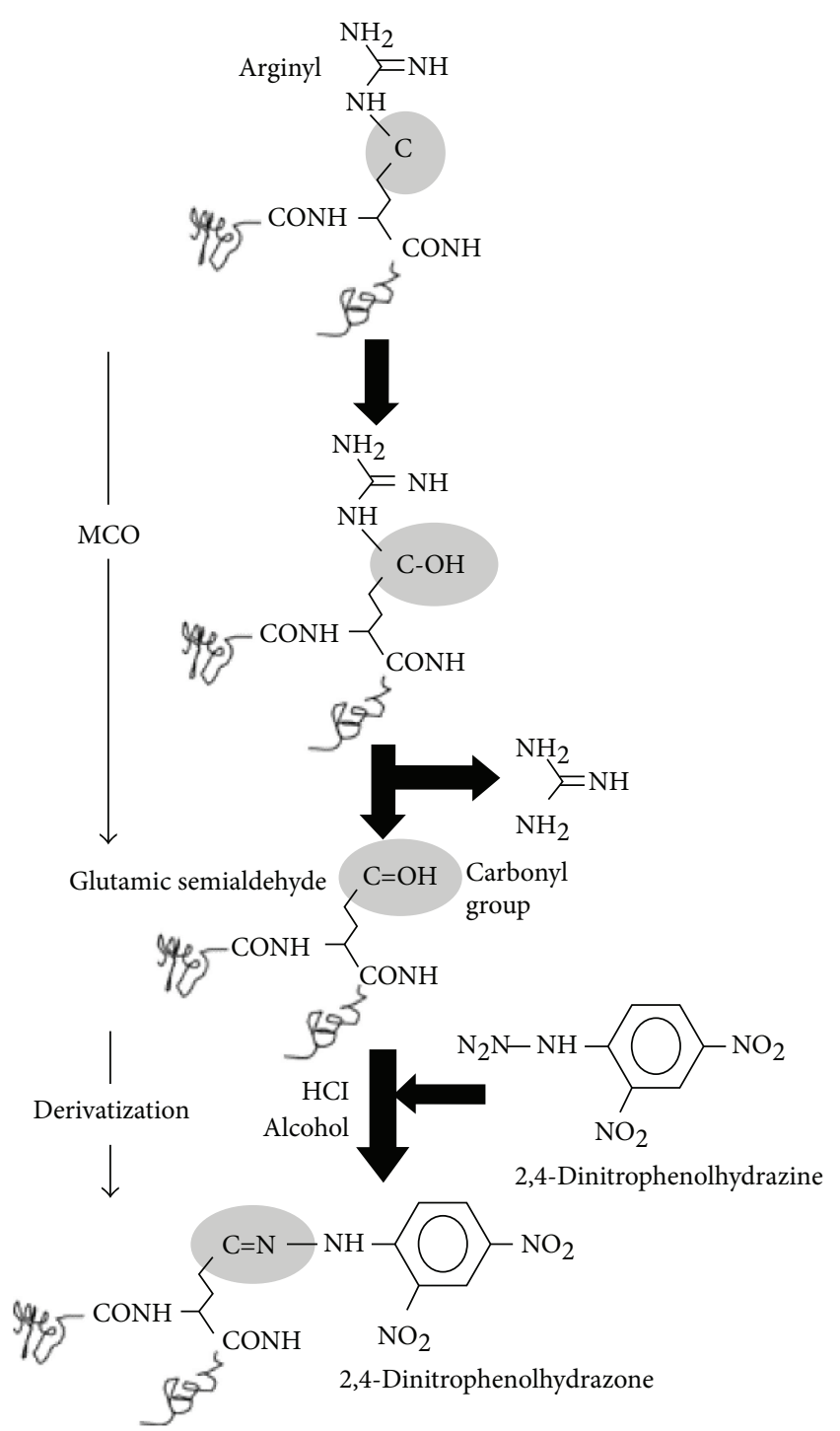

FIGURE 6: Carbonylation and derivatization of a protein amino acid side chain. A scheme for the formation of glutamic semialdehyde from an arginyl residue is depicted as a consequence of an MCO. For detection, the carbonyl group, in this case, glutamic semialdehyde, is subsequently derivatized by 2,4-dinitrophenolhydrazine. The resulting protein 2,4-dinitrophenolhydrazone can be detected by specific monoclonal or polyclonal antibodies [210]. Reproduced with permission from Nyström T. Role of oxidative carbonylation in protein quality control and senescence. The EMBO Journal. 2005; 24 (7):1311-1317. doi:10.1038/sj.emboj.7600599.

lacking Sigma-S have elevated levels of proteins with oxidative damage $[254,256]$ and accelerated senescence during growth arrest [272]. In Salmonella sp., both Sigma-S and Sigma-E are required for protection against oxidative damage in the stationary phase and mutants lacking Sigma-E have reduced survival and increased susceptibility to oxidative stress [273]. However, under anaerobic stationary-phase conditions, survival is completely preserved [273], indicating that oxidative injury is a major mechanism by which microbial viability is reduced during nutrient deprivation. Interestingly, members of the Sigma-S regulon include a

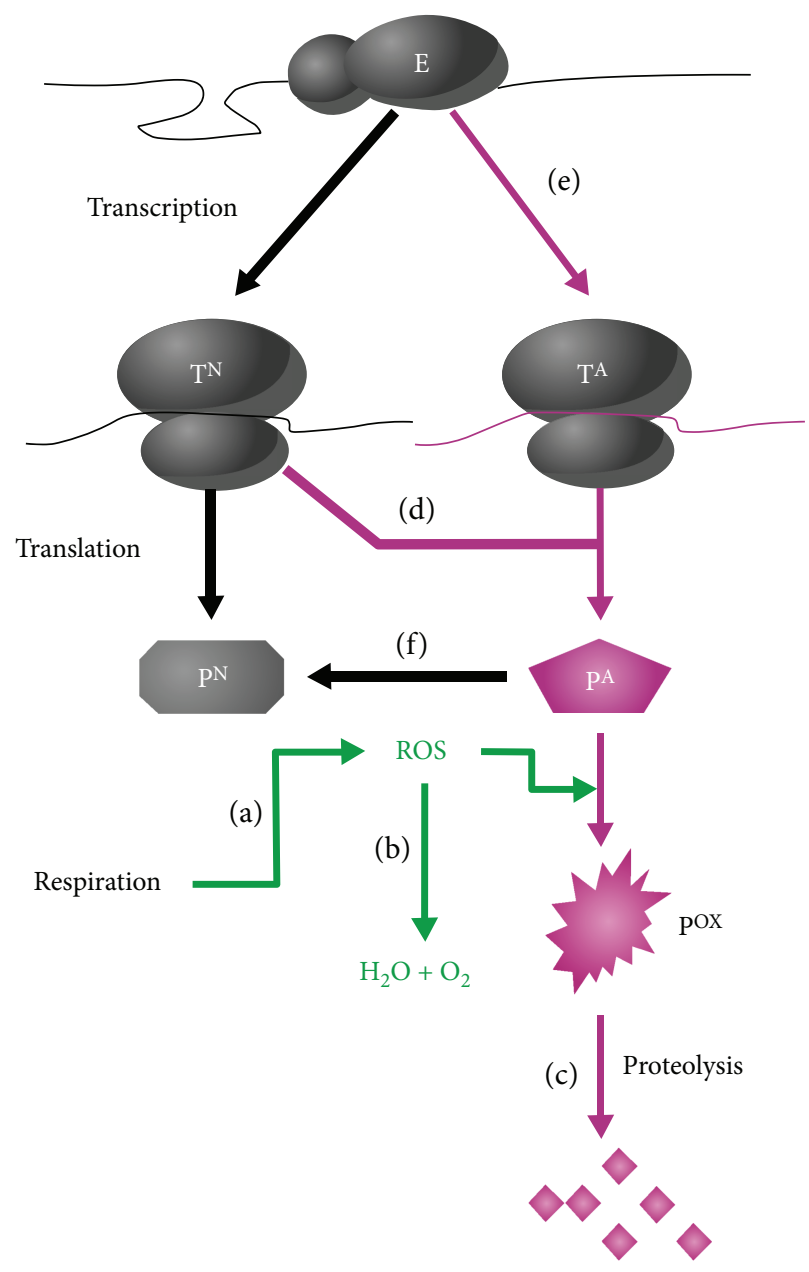

FIgURE 7: Activities of potential importance for stasis-induced oxidation of proteins. Traditionally, increased protein oxidation has been argued to be an effect of (a) increased production of reactive oxygen species (ROS), presumably derived from respiratory activity, (b) diminished activity or abundance of the antioxidant systems, or (c) reduced activity of the proteolysis or damage repair systems. Work on E. coli has highlighted the role of some alternative pathways in protein oxidation. These pathways relate to the production of aberrant proteins, which are highly susceptible to oxidative modification (carbonylation). Increased levels of such aberrant, malformed polypeptides can be the result of (d) reduced translational fidelity, (e) reduced transcriptional fidelity, or (f) diminished activity of the repair refolding apparatus. In the early stages of $E$. coli growth arrest, reduced translational fidelity appears to be the most important contributing factor to the elevated levels of oxidatively modified aberrant proteins. E, core RNA polymerase; $\mathrm{P}^{\mathrm{A}}$, aberrant protein; $\mathrm{P}^{\mathrm{N}}$, native protein; $\mathrm{P}^{\mathrm{ox}}$, oxidized protein; $\mathrm{T}^{\mathrm{A}}$, aberrant transcript; $\mathrm{T}^{\mathrm{N}}$, native transcript. Reproduced with permission from Nyström, Thomas. "Aging in bacteria." Current Opinion in Microbiology 5, no. 6 (2002): 596-601.

diverse set of proteins with functions that overlap those of FOXO-/daf-16-regulated longevity genes in C. elegans [142, 147, 148]. Thus, functionally similar signaling pathways seem to regulate stress resistance, protein damage protection, and longevity in eukaryotes and prokaryotes. These pathways are pivotal for survival during periods of 
starvation. They may have been evolutionarily conserved across different branches of the tree of life because they enhanced the maintenance capacity of the cell. Over time, they also may have become crucial for retarding aging in multicellular organisms [143, 149].

7.2. Genetic Determinants of Senescence and Aging in Bacteria. Literature investigating the genes that extend stationary-phase survival in bacteria is scarce. However, a few mutant strains that survive longer than WT have been reported. RssB, which regulates the stability of the sigma factor Sigma-S, has been found to play a key role in the survival of $E$. coli, potentially by increasing the cell's resistance to spontaneous, endogenous stresses [274].

More recently, a genome-wide screen for E. coli mutants with a prolonged stationary-phase survival phenotype identified three strains that lived longer than WT [275]. One of the strains, $\Delta s d h A$ (succinate dehydrogenase subunit A), displayed increased stress resistance and extended lifespan. Succinate dehydrogenase is a tetrameric protein complex that catalyzes the conversion of succinate to fumarate in the TCA cycle [276]. Subunit A, the enzymatically active part of the complex, is a well-established source of superoxide in the ETC of E. coli [277]. Purportedly, when this enzyme is absent, the rate of superoxide production is reduced, extending stationary-phase survival [275].

The two other mutants displaying extended stationaryphase survival were $\Delta l i p A$ (lipoyl synthase) and $\Delta l p d A$ (dihydrolipoyl dehydrogenase) [275]. The authors attributed the enhanced lifespan of these two mutants to their reduced consumption of oxygen, compared to WT, which in turn increased the expression of the hypoxia transcription factor ArcA [278]. ArcA suppresses the expression of TCA cycle genes, such as citrate synthase (gltA), and activates the expression of genes required to generate energy under oxygen-limited conditions, extending stationary-phase survival [279]. These observations suggest that the extended lifespan observed in these mutants is associated with the induction of a physiological state typically associated with hypoxic conditions. These results are consistent with the lifespan-modulating role of HIF- $1 \alpha$ in higher organisms $[37,162,163]$. In fact, ArcA could be considered a functional homolog of HIF-1 $\alpha$, although the two proteins do not share significant sequence similarity. This functional similarity points toward the adaptive response to oxygen-limited conditions as an evolutionarily conserved mechanism that can extend lifespan.

Given the conservation of key phenotypes associated with age-dependent macromolecular damage and the lifespan-extending role of genes that control the hypoxic response in both bacteria and higher eukaryotes, it is reasonable to hypothesize that the most fundamental mechanisms of aging might be conserved at all levels of life. Future studies will help to clarify what molecular processes underlying aging are similar between bacteria and eukaryotes. The results of these studies could open the possibility of using $E$. coli as a model organism of aging on which specific molecular mechanisms and evolutionary theories can be easily tested.

\section{Conclusions and Future Perspectives}

The progressive loss of mitochondrial function is a consistent and conserved hallmark of aging that impacts both cellular homeostasis and organismal health $[134,135]$. While ROS contribute to aging, they also play a crucial role in cell signaling and development, thus serving a beneficial role. The mitochondrial theory of aging offers a conciliatory perspective of the dual role of ROS in the aging process by incorporating two important adaptive responses: (1) UPRmt-mediated retrograde signaling from the mitochondria to the nucleus to regulate aging and (2) ROS-mediated adaptive response to activate the antioxidant defense system of the cell. Interventions targeting either of these two adaptive pathways could be considered potential targets for antiaging and lifespan-promoting therapies.

Because the accumulation of oxidative damage throughout life is a major cause of aging, genetic or pharmacological interventions targeting oxidative damage repair or damage removal pathways themselves also have significant therapeutic potential. However, further research in humans and nonhuman primates is needed to gain insights into the clinical significance of potential genetic, pharmacological, and nonpharmacological interventions.

The observation that several of the processes that characterize eukaryotic aging can also be seen in bacteria highlights the potential of bacteria to serve as a simple model organism to study aging and age-related mechanisms. These tractable models might provide crucial assistance in the quest to uncover the genetic, molecular, and biochemical processes underlying aging and age-related diseases.

\section{Disclosure}

The funders had no role in the study design, data collection, and analysis, decision to publish, or preparation of the manuscript. Sanchari Sinha's current address is Independent Science Writer, Kolkata, India.

\section{Conflicts of Interest}

The authors declare no conflict of interest regarding the content of this paper.

\section{Acknowledgments}

Acknowledgments are due to the anonymous reviewer for a detailed analysis and helpful criticism of the previous version of this manuscript. The authors would also like to acknowledge Dr. Nathan Susnik (Hanover Medical School, Hanover, Germany) for his insightful comments and thoughtful advice. The authors gratefully acknowledge the AXA Research Fund (http://www.axa-research.org/) for their support.

\section{References}

[1] L. Partridge and D. Gems, "Mechanisms of ageing: public or private?," Nature Reviews Genetic, vol. 3, no. 3, pp. 165$175,2002$. 
[2] P. Davalli, T. Mitic, A. Caporali, A. Lauriola, and D. D'Arca, "ROS, cell senescence, and novel molecular mechanisms in aging and age-related diseases," Oxidative Medicine and Cellular Longevity, vol. 2016, Article ID 3565127, 18 pages, 2016.

[3] World Health Organization, "World report on aging and health," 2015.

[4] E. A. Kikis, T. Gidalevitz, and R. I. Morimoto, "Protein homeostasis in models of aging and age-related conformational disease," Experimental Medicine and Biology, vol. 694, pp. 138-159, 2010.

[5] K. Jin, J. W. Simpkins, X. Ji, M. Leis, and I. Stambler, "The critical need to promote research of aging and aging-related diseases to improve health and longevity of the elderly population," Aging and Disease, vol. 6, no. 1, pp. 1-5, 2015.

[6] R. J. Mailloux, "Teaching the fundamentals of electron transfer reactions in mitochondria and the production and detection of reactive oxygen species," Redox Biology, vol. 4, pp. 381-398, 2015.

[7] D. Harman, "Aging: a theory based on free radical and radiation chemistry," Journal of Gerontology, vol. 11, no. 3, pp. 298-300, 1956.

[8] K. Krumova and G. Cosa, "Chapter 1. Overview of reactive oxygen species," in Singlet Oxygen: Applications in Biosciences and Nanosciences, Volume 1, pp. 1-21, The Royal Society of Chemistry, 2016.

[9] V. K. Koltover, "Free radical timer of aging: from chemistry of free radicals to systems theory of reliability," Current Aging Science, vol. 10, no. 1, pp. 12-17, 2017.

[10] G. Barja, "Chapter one - The mitochondrial free radical theory of aging," in The Mitochondrion in Aging and Disease, pp. 1-27, Academic Press, 2014.

[11] M. Ristow and S. Schmeisser, "Extending life span by increasing oxidative stress," Free Radical Biology and Medicine, vol. 51, no. 2, pp. 327-336, 2011.

[12] J. M. Van Raamsdonk and S. Hekimi, "Superoxide dismutase is dispensable for normal animal lifespan," Proceedings of the National Academy of Sciences, vol. 109, no. 15, pp. 57855790,2012

[13] J. Lapointe and S. Hekimi, "When a theory of aging ages badly," Cellular and Molecular Life Sciences, vol. 67, no. 1, pp. 1-8, 2010.

[14] D. Gems and R. Doonan, "Antioxidant defense and aging in C. elegans: is the oxidative damage theory of aging wrong?," Cell Cycle, vol. 8, no. 11, pp. 1681-1687, 2009.

[15] M. Ristow and K. Zarse, "How increased oxidative stress promotes longevity and metabolic health: the concept of mitochondrial hormesis (mitohormesis)," Experimental Gerontology, vol. 45, no. 6, pp. 410-418, 2010.

[16] M. Ristow and K. Schmeisser, "Mitohormesis: promoting health and lifespan by increased levels of reactive oxygen species (ROS)," Dose-Response, vol. 12, no. 2, pp. 288-341, 2014.

[17] T. Ogawa, Y. Kodera, D. Hirata, T. K. Blackwell, and M. Mizunuma, "Natural thioallyl compounds increase oxidative stress resistance and lifespan in Caenorhabditis elegans by modulating SKN-1/Nrf," Scientific Reports, vol. 6, no. 1, pp. 1-13, 2016.

[18] N. Fischer, C. Büchter, K. Koch, S. Albert, R. Csuk, and W. Wätjen, "The resveratrol derivatives trans-3,5dimethoxy-4-fluoro- $4^{\prime}$-hydroxystilbene and trans-2, $4^{\prime}, 5$ trihydroxystilbene decrease oxidative stress and prolong lifespan in Caenorhabditis elegans," Journal of Pharmacy and Pharmacology, vol. 69, no. 1, pp. 73-81, 2017.

[19] J. M. Van Raamsdonk and S. Hekimi, "Deletion of the mitochondrial superoxide dismutase sod-2 extends lifespan in Caenorhabditis elegans," PLoS Genetics, vol. 5, no. 2, article e1000361, 2009.

[20] W. Yang and S. Hekimi, "A mitochondrial superoxide signal triggers increased longevity in Caenorhabditis elegans," PLoS Biology, vol. 8, no. 12, article e1000556, 2010.

[21] M. Holzenberger, J. Dupont, B. Ducos et al., "IGF-1 receptor regulates lifespan and resistance to oxidative stress in mice," Nature, vol. 421, no. 6919, pp. 182-187, 2002.

[22] E. Migliaccio, M. Giorgio, S. Mele et al., "The p66shc adaptor protein controls oxidative stress response and life span in mammals," Nature, vol. 402, no. 6759, pp. 309313, 1999.

[23] Y. Zhang, A. Unnikrishnan, S. S. Deepa et al., "A new role for oxidative stress in aging: the accelerated aging phenotype in Sod1 $1^{-/}$mice is correlated to increased cellular senescence," Redox Biology, vol. 11, pp. 30-37, 2017.

[24] S. E. Schriner, N. J. Linford, G. M. Martin et al., "Extension of murine life span by overexpression of catalase targeted to mitochondria," Science, vol. 308, no. 5730, pp. 1909-1911, 2005

[25] P. M. Treuting, N. J. Linford, S. E. Knoblaugh et al., "Reduction of age-associated pathology in old mice by overexpression of catalase in mitochondria," The Journals of Gerontology Series A: Biological Sciences and Medical Sciences, vol. 63, no. 8, pp. 813-822, 2008.

[26] T. T. Huang, E. J. Carlson, A. M. Gillespie, Y. Shi, and C. J. Epstein, "Ubiquitous overexpression of CuZn superoxide dismutase does not extend life span in mice," The Journals of Gerontology Series A: Biological Sciences and Medical Sciences, vol. 55, pp. B5-B9, 2000.

[27] V. I. Perez, H. Van Remmen, A. Bokov, C. J. Epstein, J. Vijg, and A. Richardson, "The overexpression of major antioxidant enzymes does not extend the lifespan of mice," Aging Cell, vol. 8, no. 1, pp. 73-75, 2009.

[28] Y. S. Ho, J. L. Magnenat, R. T. Bronson et al., "Mice deficient in cellular glutathione peroxidase develop normally and show no increased sensitivity to hyperoxia," Journal of Biological Chemistry, vol. 272, no. 26, pp. 16644-16651, 1997.

[29] Y. Zhang, Y. Ikeno, W. Qi et al., "Mice deficient in both Mn superoxide dismutase and glutathione peroxidase-1 have increased oxidative damage and a greater incidence of pathology but no reduction in longevity," The Journals of Gerontology Series A: Biological Sciences and Medical Sciences, vol. 64A, no. 12, pp. 1212-1220, 2009.

[30] M. Soerensen, K. Christensen, T. Stevnsner, and L. Christiansen, "The Mn-superoxide dismutase single nucleotide polymorphism rs4880 and the glutathione peroxidase 1 single nucleotide polymorphism rs1050450 are associated with aging and longevity in the oldest old," Mechanisms of Ageing and Development, vol. 130, no. 5, pp. 308-314, 2009.

[31] S.-E. Yoo, L. Chen, R. Na et al., "Gpx4 ablation in adult mice results in a lethal phenotype accompanied by neuronal loss in brain," Free Radical Biology and Medicine, vol. 52, no. 9, pp. 1820-1827, 2012. 
[32] Q. Ran, H. Liang, M. Gu et al., "Transgenic mice overexpressing glutathione peroxidase 4 are protected against oxidative stress-induced apoptosis," Journal of Biological Chemistry, vol. 279, no. 53, pp. 55137-55146, 2004.

[33] V. I. Pérez, A. Bokov, H. Van Remmen et al., "Is the oxidative stress theory of aging dead?," Biochimica et Biophysica Acta (BBA) - General Subjects, vol. 1790, no. 10, pp. 1005-1014, 2009.

[34] L. Nonn, R. R. Williams, R. P. Erickson, and G. Powis, "The absence of mitochondrial thioredoxin 2 causes massive apoptosis, exencephaly, and early embryonic lethality in homozygous mice," Molecular and Cellular Biology, vol. 23, no. 3, pp. 916-922, 2003.

[35] V. I. Pérez, C. M. Lew, L. A. Cortez et al., "Thioredoxin 2 haploinsufficiency in mice results in impaired mitochondrial function and increased oxidative stress," Free Radical Biology and Medicine, vol. 44, no. 5, pp. 882-892, 2008.

[36] V. I. Pérez, L. A. Cortez, C. M. Lew et al., "Thioredoxin 1 overexpression extends mainly the earlier part of life span in mice," The Journals of Gerontology Series A: Biological Sciences and Medical Sciences, vol. 66A, no. 12, pp. 1286-1299, 2011.

[37] C. E. Schaar, D. J. Dues, K. K. Spielbauer et al., "Mitochondrial and cytoplasmic ROS have opposing effects on lifespan," PLOS Genetics, vol. 11, no. 2, article e1004972, 2015.

[38] F. Scialò, A. Sriram, D. Fernández-Ayala et al., "Mitochondrial ROS produced via reverse electron transport extend animal lifespan," Cell Metabolism, vol. 23, no. 4, pp. 725-734, 2016.

[39] X. Liu, N. Jiang, B. Hughes, E. Bigras, E. Shoubridge, and S. Hekimi, "Evolutionary conservation of the clk-1dependent mechanism of longevity: loss of mclk1 increases cellular fitness and lifespan in mice," Genes \& Development, vol. 19, no. 20, pp. 2424-2434, 2005.

[40] C. Dell'Agnello, S. Leo, A. Agostino et al., "Increased longevity and refractoriness to $\mathrm{Ca}(2+)$-dependent neurodegeneration in Surf1 knockout mice," Human Molecular Genetics, vol. 16, no. 4, pp. 431-444, 2007.

[41] J. M. Van Raamsdonk, Y. Meng, D. Camp et al., "Decreased energy metabolism extends life span in Caenorhabditis elegans without reducing oxidative damage," Genetics, vol. 185, no. 2, pp. 559-571, 2010.

[42] T. Lindahl and D. E. Barnes, "Repair of Endogenous DNA Damage," Cold Spring Harbor Symposia on Quantitative Biology, vol. 65, no. 0, pp. 127-134, 2000.

[43] H. L. Gensler and H. Bernstein, "DNA damage as the primary cause of aging," The Quarterly Review of Biology, vol. 56, no. 3, pp. 279-303, 1981.

[44] L. Szilard, "On the nature of the aging process," Proceedings of the National Academy of Sciences, vol. 45, no. 1, pp. 3045, 1959.

[45] M. M. Vilenchik and A. G. Knudson, "Inverse radiation dose-rate effects on somatic and germ-line mutations and DNA damage rates," Proceedings of the National Academy of Sciences, vol. 97, no. 10, pp. 5381-5386, 2000.

[46] T. Lindahl and B. Nyberg, "Heat-induced deamination of cytosine residues in deoxyribonucleic acid," Biochemistry, vol. 13, no. 16, pp. 3405-3410, 1974.

[47] T. Lindahl and B. Nyberg, "Rate of depurination of native deoxyribonucleic acid," Biochemistry, vol. 11, no. 19, pp. 3610-3618, 1974.
[48] F. R. de Gruijl and H. Rebel, "Early events in UV carcinogenesis-DNA damage, target cells and mutant p53 foci," Photochemistry and Photobiology, vol. 84, no. 2, pp. 382-387, 2008.

[49] M. C. Poirier, R. M. Santella, and A. Weston, "Carcinogen macromolecular adducts and their measurement," Carcinogenesis, vol. 21, no. 3, pp. 353-359, 2000.

[50] K. A. Cimprich and D. Cortez, "ATR: an essential regulator of genome integrity," Nature Reviews Molecular Cell Biology, vol. 9, no. 8, pp. 616-627, 2008.

[51] F. Lazzaro, M. Giannattasio, F. Puddu et al., "Checkpoint mechanisms at the intersection between DNA damage and repair," DNA Repair, vol. 8, no. 9, pp. 1055-1067, 2009.

[52] S. Dukan, A. Farewell, M. Ballesteros, F. Taddei, M. Radman, and T. Nyström, "Protein oxidation in response to increased transcriptional or translational errors," Proceedings of the National Academy of Sciences, vol. 97, no. 11, pp. 57465749, 2000.

[53] K. Tanaka, "The proteasome: overview of structure and functions," Proceedings of the Japan Academy, Series B, vol. 85, no. 1, pp. 12-36, 2009.

[54] T. Jung, N. Bader, and T. Grune, "Oxidized proteins: intracellular distribution and recognition by the proteasome," Archives of Biochemistry and Biophysics, vol. 462, no. 2, pp. 231-237, 2007.

[55] P. Fortini, B. Pascucci, E. Parlanti, M. D'Errico, V. Simonelli, and E. Dogliotti, "8-Oxoguanine DNA damage: at the crossroad of alternative repair pathways," Mutation Research/Fundamental and Molecular Mechanisms of Mutagenesis, vol. 531, no. 1-2, pp. 127-139, 2003.

[56] H. E. Krokan and M. Bjoras, "Base excision repair," Cold Spring Harbor Perspectives in Biology, vol. 5, no. 4, article a012583, 2013.

[57] O. D. Scharer, "Nucleotide excision repair in eukaryotes," Cold Spring Harbor Perspectives in Biology, vol. 5, no. 10, article a012609, 2013.

[58] M. R. Lieber, "The mechanism of double-strand DNA break repair by the nonhomologous DNA end-joining pathway," Annual Review of Biochemistry, vol. 79, no. 1, pp. 181-211, 2010.

[59] J. K. Moore and J. E. Haber, "Cell cycle and genetic requirements of two pathways of nonhomologous end-joining repair of double-strand breaks in Saccharomyces cerevisiae," Molecular and Cellular Biology, vol. 16, no. 5, pp. 2164-2173, 1996.

[60] G. Xu, M. Herzig, V. Rotrekl, and C. A. Walter, "Base excision repair, aging and health span," Mechanisms of Ageing and Development, vol. 129, no. 7-8, pp. 366-382, 2008.

[61] R. Mostoslavsky, K. F. Chua, D. B. Lombard et al., "Genomic instability and aging-like phenotype in the absence of mammalian SIRT6," Cell, vol. 124, no. 2, pp. 315-329, 2006.

[62] J. Kanungo, "DNA-dependent protein kinase and DNA repair: relevance to Alzheimer's disease," Alzheimer's Research \& Therapy, vol. 5, no. 2, p. 13, 2013.

[63] V. N. Vyjayanti and K. S. Rao, "DNA double strand break repair in brain: reduced NHEJ activity in aging rat neurons," Neuroscience Letters, vol. 393, no. 1, pp. 18-22, 2006.

[64] J. German, "Bloom syndrome: a mendelian prototype of somatic mutational disease," Medicine, vol. 72, no. 6, pp. 393-406, 1993.

[65] C. J. Epstein, G. M. Martin, A. L. Schultz, and A. G. Motulsky, "A review of its symptomatology, natural history, pathologic 
features, genetics and relationship to the natural aging process," Medicine, vol. 45, no. 3, pp. 177-221, 1966.

[66] A. S. Balajee, A. Machwe, A. May et al., "The Werner syndrome protein is involved in RNA polymerase II transcription," Molecular Biology of the Cell, vol. 10, no. 8, pp. 2655-2668, 1999.

[67] B. Li and L. Comai, "Functional interaction between $\mathrm{Ku}$ and the werner syndrome protein in DNA end processing," Journal of Biological Chemistry, vol. 275, no. 37, pp. 28349-28352, 2000.

[68] P. Hasty, "The impact of DNA damage, genetic mutation and cellular responses on cancer prevention, longevity and aging: observations in humans and mice," Mechanisms of Ageing and Development, vol. 126, no. 1, pp. 71-77, 2005.

[69] J. H. J. Hoeijmakers, “DNA damage, aging, and cancer," New England Journal of Medicine, vol. 361, no. 15, pp. 1475-1485, 2009.

[70] K. Kashiyama, Y. Nakazawa, D. T. Pilz et al., "Malfunction of nuclease ERCC1-XPF results in diverse clinical manifestations and causes Cockayne syndrome, xeroderma pigmentosum, and Fanconi anemia," The American Journal of Human Genetics, vol. 92, no. 5, pp. 807-819, 2013.

[71] L. J. Niedernhofer, G. A. Garinis, A. Raams et al., "A new progeroid syndrome reveals that genotoxic stress suppresses the somatotroph axis," Nature, vol. 444, no. 7122, pp. 1038-1043, 2006.

[72] M. A. Blasco, "Telomere length, stem cells and aging," Nature Chemical Biology, vol. 3, no. 10, pp. 640-649, 2007.

[73] H. Vallabhaneni, F. Zhou, R. W. Maul et al., "Defective repair of uracil causes telomere defects in mouse hematopoietic cells," Journal of Biological Chemistry, vol. 290, no. 9, pp. 5502-5511, 2015.

[74] H. Vallabhaneni, N. O'Callaghan, J. Sidorova, and Y. Liu, "Defective repair of oxidative base lesions by the DNA glycosylase Nth1 associates with multiple telomere defects," PLoS Genetics, vol. 9, no. 7, article e1003639, 2013.

[75] C. Richter, J. W. Park, and B. N. Ames, "Normal oxidative damage to mitochondrial and nuclear DNA is extensive," Proceedings of the National Academy of Sciences, vol. 85, no. 17, pp. 6465-6467, 1988.

[76] S. P. Ledoux and G. L. Wilson, "Base excision repair of mitochondrial DNA damage in mammalian cells," Progress in Nucleic Acid Research and Molecular Biology, vol. 68, pp. 273-284, 2001.

[77] W. J. Driggers, S. P. LeDoux, and G. L. Wilson, "Repair of oxidative damage within the mitochondrial DNA of RINr 38 cells," Journal of Biological Chemistry, vol. 268, no. 29, pp. 22042-22045, 1993.

[78] G. L. Dianov, N. Souza-Pinto, S. G. Nyaga, T. Thybo, T. Stevnsner, and V. A. Bohr, "Base excision repair in nuclear and mitochondrial DNA," Progress in Nucleic Acid Research and Molecular Biology, vol. 68, pp. 285-297, 2001.

[79] J. A. Stuart, K. Hashiguchi, D. M. Wilson 3rd, W. C. Copeland, N. C. Souza-Pinto, and V. A. Bohr, "DNA base excision repair activities and pathway function in mitochondrial and cellular lysates from cells lacking mitochondrial DNA," Nucleic Acids Research, vol. 32, no. 7, pp. 2181-2192, 2004.

[80] R. Chattopadhyay, L. Wiederhold, B. Szczesny et al., "Identification and characterization of mitochondrial abasic
(AP)-endonuclease in mammalian cells," Nucleic Acids Research, vol. 34, no. 7, pp. 2067-2076, 2006.

[81] A. Bender, K. J. Krishnan, C. M. Morris et al., "High levels of mitochondrial DNA deletions in substantia nigra neurons in aging and Parkinson disease," Nature Genetics, vol. 38, no. 5, pp. 515-517, 2006.

[82] A. Trifunovic, A. Hansson, A. Wredenberg et al., "Somatic mtDNA mutations cause aging phenotypes without affecting reactive oxygen species production," Proceedings of the National Academy of Sciences, vol. 102, no. 50, pp. 1799317998, 2005.

[83] J. N. Octave, "Alzheimer disease: cellular and molecular aspects," Bulletin et memoires de l'Academie royale de medecine de Belgique, vol. 160, pp. 441-445, 2005.

[84] A. Chomyn and G. Attardi, "MtDNA mutations in aging and apoptosis," Biochemical and Biophysical Research Communications, vol. 304, no. 3, pp. 519-529, 2003.

[85] P. E. Coskun, M. F. Beal, and D. C. Wallace, “Alzheimer's brains harbor somatic mtDNA control-region mutations that suppress mitochondrial transcription and replication," Proceedings of the National Academy of Sciences, vol. 101, no. 29, pp. 10726-10731, 2004.

[86] M. T. Lin, D. K. Simon, C. H. Ahn, L. M. Kim, and M. F. Beal, "High aggregate burden of somatic mtDNA point mutations in aging and Alzheimer's disease brain," Human Molecular Genetics, vol. 11, no. 2, pp. 133-145, 2002.

[87] T. Nystrom, "Role of oxidative carbonylation in protein quality control and senescence," The EMBO Journal, vol. 24, no. 7, pp. 1311-1317, 2005.

[88] Y. J. Suzuki, M. Carini, and D. A. Butterfield, "Protein carbonylation," Antioxidants \& Redox Signaling, vol. 12, no. 3, pp. 323-325, 2010.

[89] Q. Chen, J. Thorpe, J. R. Dohmen, F. Li, and J. N. Keller, "Ump1 extends yeast lifespan and enhances viability during oxidative stress: central role for the proteasome?," Free Radical Biology and Medicine, vol. 40, no. 1, pp. 120-126, 2006.

[90] L. Knuppertz and H. D. Osiewacz, "Orchestrating the network of molecular pathways affecting aging: role of nonselective autophagy and mitophagy," Mechanisms of Ageing and Development, vol. 153, pp. 30-40, 2016.

[91] Q. Zhao, J. Wang, I. V. Levichkin, S. Stasinopoulos, M. T. Ryan, and N. J. Hoogenraad, "A mitochondrial specific stress response in mammalian cells," The EMBO Journal, vol. 21, no. 17, pp. 4411-4419, 2002.

[92] T. Yoneda, C. Benedetti, F. Urano, S. G. Clark, H. P. Harding, and D. Ron, "Compartment-specific perturbation of protein handling activates genes encoding mitochondrial chaperones," Journal of Cell Science, vol. 117, no. 18, pp. 40554066, 2004.

[93] C. O'Neill, A. P. Kiely, M. F. Coakley, S. Manning, and C. M. Long-Smith, "Insulin and IGF-1 signalling: longevity, protein homoeostasis and Alzheimer's disease," Biochemical Society Transactions, vol. 40, no. 4, pp. 721-727, 2012.

[94] J. F. Morley and R. I. Morimoto, "Regulation of longevity in Caenorhabditis elegans by heat shock factor and molecular chaperones," Molecular Biology of the Cell, vol. 15, no. 2, pp. 657-664, 2003.

[95] E. Cohen, J. Bieschke, R. M. Perciavalle, J. W. Kelly, and A. Dillin, "Opposing activities protect against age-onset proteotoxicity," Science, vol. 313, no. 5793, pp. 16041610, 2006. 
[96] S. Alavez, M. C. Vantipalli, D. J. S. Zucker, I. M. Klang, and G. J. Lithgow, "Amyloid-binding compounds maintain protein homeostasis during ageing and extend lifespan," Nature, vol. 472, no. 7342, pp. 226-229, 2011.

[97] M. J. Vos, S. Carra, B. Kanon et al., "Specific protein homeostatic functions of small heat-shock proteins increase lifespan,” Aging Cell, vol. 15, no. 2, pp. 217-226, 2016.

[98] S. Kaushik and A. M. Cuervo, "Proteostasis and aging," Nature Medicine, vol. 21, no. 12, pp. 1406-1415, 2015.

[99] T. Grune, "Oxidative stress, aging and the proteasomal system," Biogerontology, vol. 1, no. 1, pp. 31-40, 2000.

[100] P. A. Szweda, M. Camouse, K. C. Lundberg, T. D. Oberley, and L. I. Szweda, "Aging, lipofuscin formation, and free radical-mediated inhibition of cellular proteolytic systems," Ageing Research Reviews, vol. 2, no. 4, pp. 383-405, 2003.

[101] Q. Ding, E. Dimayuga, W. R. Markesbery, and J. N. Keller, "Proteasome inhibition induces reversible impairments in protein synthesis," The FASEB Journal, vol. 20, no. 8, pp. 1055-1063, 2006.

[102] Q. Ding, E. Dimayuga, and J. N. Keller, "Proteasome regulation of oxidative stress in aging and age-related diseases of the CNS," Antioxidants \& Redox Signaling, vol. 8, no. 1-2, pp. 163-172, 2006.

[103] A. L. Santos and A. B. Lindner, "Protein posttranslational modifications: roles in aging and age-related disease," Oxidative Medicine and Cellular Longevity, vol. 2017, Article ID 5716409, 19 pages, 2017.

[104] J. N. Keller, F. F. Huang, and W. R. Markesbery, "Decreased levels of proteasome activity and proteasome expression in aging spinal cord," Neuroscience, vol. 98, no. 1, pp. 149-156, 2000.

[105] J. N. Keller, K. B. Hanni, and W. R. Markesbery, "Possible involvement of proteasome inhibition in aging: implications for oxidative stress," Mechanisms of Ageing and Development, vol. 113, no. 1, pp. 61-70, 2000.

[106] E. Kevei and T. Hoppe, "Ubiquitin sets the timer: impacts on aging and longevity," Nature Structural \& Molecular Biology, vol. 21, no. 4, pp. 290-292, 2014.

[107] N. Hoe, C. M. Huang, G. Landis et al., "Ubiquitin overexpression phenotypes and ubiquitin gene molecular misreading during aging in Drosophila melanogaster," Aging, vol. 3, no. 3, pp. 237-261, 2011.

[108] H.-Y. Liu and C. M. Pfleger, "Mutation in E1, the ubiquitin activating enzyme, reduces Drosophila lifespan and results in motor impairment," PLoS One, vol. 8, no. 1, article e32835, 2013.

[109] A. C. Carrano, A. Dillin, and T. Hunter, "A Krüppel-like factor downstream of the E3 ligase WWP-1 mediates dietary-restriction-induced longevity in Caenorhabditis elegans," Nature Communications, vol. 5, 2014.

[110] R. A. Gottlieb and R. S. Carreira, "Autophagy in health and disease. 5. Mitophagy as a way of life," American Journal of Physiology-Cell Physiology, vol. 299, no. 2, pp. C203-C210, 2010.

[111] S. Mai, B. Muster, J. Bereiter-Hahn, and M. Jendrach, "Autophagy proteins LC3B, ATG5 and ATG12 participate in quality control after mitochondrial damage and influence lifespan," Autophagy, vol. 8, no. 1, pp. 47-62, 2014.

[112] J. N. Keller, E. Dimayuga, Q. Chen, J. Thorpe, J. Gee, and Q. Ding, "Autophagy, proteasomes, lipofuscin, and oxidative stress in the aging brain," The International Journal of Biochemistry \& Cell Biology, vol. 36, no. 12, pp. 23762391, 2004.

[113] T. Hara, K. Nakamura, M. Matsui et al., "Suppression of basal autophagy in neural cells causes neurodegenerative disease in mice," Nature, vol. 441, no. 7095, pp. 885-889, 2006.

[114] M. Dodson, V. Darley-Usmar, and J. Zhang, "Cellular metabolic and autophagic pathways: traffic control by redox signaling," Free Radical Biology and Medicine, vol. 63, pp. 207-221, 2013.

[115] K. Palikaras, E. Lionaki, and N. Tavernarakis, "Coordination of mitophagy and mitochondrial biogenesis during ageing in C. elegans," Nature, vol. 521, no. 7553, pp. 525-528, 2015.

[116] A. Rana, M. Rera, and D. W. Walker, "Parkin overexpression during aging reduces proteotoxicity, alters mitochondrial dynamics, and extends lifespan," Proceedings of the National Academy of Sciences, vol. 110, no. 21, pp. 8638-8643, 2013.

[117] J. Lee, S. Giordano, and J. Zhang, “Autophagy, mitochondria and oxidative stress: cross-talk and redox signalling," Biochemical Journal, vol. 441, no. 2, pp. 523-540, 2012.

[118] E. F. Fang, M. Scheibye-Knudsen, K. F. Chua, M. P. Mattson, D. L. Croteau, and V. A. Bohr, "Nuclear DNA damage signalling to mitochondria in ageing," Nature Reviews Molecular Cell Biology, vol. 17, no. 5, pp. 308-321, 2016.

[119] P. Bai, C. Cantó, H. Oudart et al., "PARP-1 inhibition increases mitochondrial metabolism through SIRT1 activation," Cell Metabolism, vol. 13, no. 4, pp. 461-468, 2011.

[120] S. Imai and L. Guarente, "NAD(+) and sirtuins in aging and disease," Trends in Cell Biology, vol. 24, no. 8, pp. 464-471, 2014.

[121] S. Park, R. Mori, and I. Shimokawa, "Do sirtuins promote mammalian longevity?: a critical review on its relevance to the longevity effect induced by calorie restriction," Molecules and Cells, vol. 35, no. 6, pp. 474-480, 2013.

[122] K. T. Howitz, K. J. Bitterman, H. Y. Cohen et al., "Small molecule activators of sirtuins extend Saccharomyces cerevisiae lifespan," Nature, vol. 425, no. 6954, pp. 191-196, 2003.

[123] E. Morselli, M. C. Maiuri, M. Markaki et al., "Caloric restriction and resveratrol promote longevity through the sirtuin-1-dependent induction of autophagy," Cell Death \& Disease, vol. 1, no. 1, article e10, 2010.

[124] E. Verdin, M. D. Hirschey, L. W. S. Finley, and M. C. Haigis, "Sirtuin regulation of mitochondria: energy production, apoptosis, and signaling," Trends in Biochemical Sciences, vol. 35, no. 12, pp. 669-675, 2010.

[125] E. F. Fang, M. Scheibye-Knudsen, L. E. Brace et al., "Defective mitophagy in XPA via PARP1 hyperactivation and NAD+/SIRT1 reduction," Cell, vol. 157, no. 4, pp. 882-896, 2014.

[126] T. Radovits, L. Seres, D. Gerő et al., "Single dose treatment with PARP-inhibitor INO-1001 improves aging-associated cardiac and vascular dysfunction," Experimental Gerontology, vol. 42, no. 7, pp. 676-685, 2007.

[127] P. Pacher, J. G. Mabley, F. G. Soriano, L. Liaudet, K. Komjáti, and C. Szabó, "Endothelial dysfunction in aging animals: the role of poly(ADP-ribose) polymerase activation," British Journal of Pharmacology, vol. 135, no. 6, pp. 1347-1350, 2002.

[128] G. Zhang, M. Chao, L. Hui et al., "Poly(ADP-ribose)polymerase 1 inhibition protects against age-dependent endothelial dysfunction," Clinical and Experimental Pharmacology and Physiology, vol. 42, no. 12, pp. 1266-1274, 2015. 
[129] S. Shall and G. de Murcia, "Poly(ADP-ribose) polymerase-1: what have we learned from the deficient mouse model?," Mutation Research/DNA Repair, vol. 460, no. 1, pp. 1-15, 2000.

[130] T. S. Piskunova, M. N. Yurova, A. I. Ovsyannikov et al., "Deficiency in poly(ADP-ribose) polymerase-1 (PARP-1) accelerates aging and spontaneous carcinogenesis in mice," Current Gerontology and Geriatrics Research, vol. 2008, Article ID 754190, 11 pages, 2008.

[131] A. Mangerich and A. Bürkle, "Pleiotropic cellular functions of PARP1 in longevity and aging: genome maintenance meets inflammation," Oxidative Medicine and Cellular Longevity, vol. 2012, Article ID 321653, 19 pages, 2012.

[132] A. A. Freitas and J. P. de Magalhaes, "A review and appraisal of the DNA damage theory of ageing," Mutation Research/ Reviews in Mutation Research, vol. 728, no. 1-2, pp. 12-22, 2011.

[133] N. J. Curtin, "DNA repair dysregulation from cancer driver to therapeutic target," Nature Reviews Cancer, vol. 12, no. 12, pp. 801-817, 2012.

[134] T. A. Prolla and J. M. Denu, "NAD ${ }^{+}$deficiency in age-related mitochondrial dysfunction," Cell Metabolism, vol. 19, no. 2, pp. 178-180, 2014.

[135] F. Li, Z. Z. Chong, and K. Maiese, "Cell life versus cell longevity: the mysteries surrounding the $\mathrm{NAD}(+)$ precursor nicotinamide," Current Medicinal Chemistry, vol. 13, no. 8, pp. 883-895, 2006.

[136] M. S. Bonkowski and D. A. Sinclair, "Slowing ageing by design: the rise of NAD+ and sirtuin-activating compounds," Nature Reviews Molecular Cell Biology, vol. 17, no. 11, pp. 679-690, 2016.

[137] S. Imai and L. Guarente, "It takes two to tango: NAD+ and sirtuins in aging/longevity control," npj Aging and Mechanisms of Disease, vol. 2, no. 1, article 16017, 2016.

[138] K. Maiese, Z. Z. Chong, J. Hou, and Y. C. Shang, "The vitamin nicotinamide: translating nutrition into clinical care," Molecules, vol. 14, no. 12, pp. 3446-3485, 2009.

[139] J. Y. Kwak, H. J. Ham, C. M. Kim, and E. S. Hwang, "Nicotinamide exerts antioxidative effects on senescent cells," Molecules and Cells, vol. 38, no. 3, pp. 229-235, 2015.

[140] K. Tsubota, "The first human clinical study for NMN has started in Japan," npj Aging and Mechanisms of Disease, vol. 2, no. 1, p. 16021, 2016.

[141] T. Hashimoto, M. Horikawa, T. Nomura, and K. Sakamoto, "Nicotinamide adenine dinucleotide extends the lifespan of Caenorhabditis elegans mediated by sir-2.1 and daf-16," Biogerontology, vol. 11, no. 1, pp. 31-43, 2010.

[142] H. Zhang, D. Ryu, Y. Wu et al., "NAD+ repletion improves mitochondrial and stem cell function and enhances life span in mice," Science, vol. 352, no. 6292, pp. 1436-1443, 2016.

[143] L. Mouchiroud, R. H. Houtkooper, N. Moullan et al., "The $\mathrm{NAD}(+) /$ sirtuin pathway modulates longevity through activation of mitochondrial UPR and FOXO signaling," Cell, vol. 154, no. 2, pp. 430-441, 2013.

[144] M. B. Jensen and H. Jasper, "Mitochondrial proteostasis in the control of aging and longevity," Cell Metabolism, vol. 20, no. 2, pp. 214-225, 2014.

[145] T. Arnould, S. Michel, and P. Renard, "Mitochondria retrograde signaling and the UPR $\mathrm{mt}$ : where are we in mammals?," International Journal of Molecular Sciences, vol. 16, no. 8, pp. 18224-18251, 2015.
[146] M. Borch Jensen, Y. Qi, R. Riley, L. Rabkina, and H. Jasper, "PGAM5 promotes lasting FoxO activation after developmental mitochondrial stress and extends lifespan in Drosophila," Elife, vol. 6, 2017.

[147] C. J. Fiorese and C. M. Haynes, "Integrating the UPRmtinto the mitochondrial maintenance network," Critical Reviews in Biochemistry and Molecular Biology, vol. 52, no. 3, pp. 304-313, 2017.

[148] K. Gariani, K. J. Menzies, D. Ryu et al., "Eliciting the mitochondrial unfolded protein response by nicotinamide adenine dinucleotide repletion reverses fatty liver disease in mice," Hepatology, vol. 63, no. 4, pp. 1190-1204, 2016.

[149] C. Lerner, A. Bitto, D. Pulliam et al., "Reduced mammalian target of rapamycin activity facilitates mitochondrial retrograde signaling and increases life span in normal human fibroblasts," Aging Cell, vol. 12, no. 6, pp. 966-977, 2013.

[150] M. Kaeberlein, D. Hu, E. O. Kerr et al., "Increased life span due to calorie restriction in respiratory-deficient yeast," PLoS Genetics, vol. 1, no. 5, article e69, 2005.

[151] S.-J. Lin, E. Ford, M. Haigis, G. Liszt, and L. Guarente, "Calorie restriction extends yeast life span by lowering the level of NADH," Genes \& Development, vol. 18, no. 1, pp. 12-16, 2004.

[152] P. Kyryakov, A. Beach, V. R. Richard et al., "Caloric restriction extends yeast chronological lifespan by altering a pattern of age-related changes in trehalose concentration," Frontiers in Physiology, vol. 3, 2012.

[153] A. Leonov, R. Feldman, A. Piano et al., "Caloric restriction extends yeast chronological lifespan via a mechanism linking cellular aging to cell cycle regulation, maintenance of a quiescent state, entry into a non-quiescent state and survival in the non-quiescent state," Oncotarget, vol. 8, no. 41, pp. 6932869350, 2017.

[154] T. L. Kaeberlein, E. D. Smith, M. Tsuchiya et al., "Lifespan extension in Caenorhabditis elegans by complete removal of food," Aging Cell, vol. 5, no. 6, pp. 487-494, 2006.

[155] B. N. Heestand, Y. Shen, W. Liu et al., "Dietary restriction induced longevity is mediated by nuclear receptor NHR-62 in Caenorhabditis elegans," PLoS Genetics, vol. 9, no. 7, article e1003651, 2013.

[156] I. Bjedov, J. M. Toivonen, F. Kerr et al., "Mechanisms of life span extension by rapamycin in the fruit fly Drosophila melanogaster," Cell Metabolism, vol. 11, no. 1, pp. 35-46, 2010.

[157] R. A. Miller, D. E. Harrison, C. M. Astle et al., "Rapamycin, but not resveratrol or simvastatin, extends life span of genetically heterogeneous mice," The Journals of Gerontology: Series A, vol. 66A, no. 2, pp. 191-201, 2011.

[158] V. N. Anisimov, M. A. Zabezhinski, I. G. Popovich et al., "Rapamycin increases lifespan and inhibits spontaneous tumorigenesis in inbred female mice," Cell Cycle, vol. 10, no. 24, pp. 4230-4236, 2011.

[159] D. E. Harrison, R. Strong, Z. D. Sharp et al., "Rapamycin fed late in life extends lifespan in genetically heterogeneous mice," Nature, vol. 460, no. 7253, pp. 392-395, 2009.

[160] R. J. Colman, T. M. Beasley, J. W. Kemnitz, S. C. Johnson, R. Weindruch, and R. M. Anderson, "Caloric restriction reduces age-related and all-cause mortality in rhesus monkeys," Nature Communications, vol. 5, 2014.

[161] C. K. Martin, L. K. Heilbronn, L. de Jonge et al., "Effect of calorie restriction on resting metabolic rate and 
spontaneous physical activity," Obesity, vol. 15, no. 12, pp. 2964-2973, 2007.

[162] K. Hagopian, J. J. Ramsey, and R. Weindruch, "Enzymes of glycerol and glyceraldehyde metabolism in mouse liver: effects of caloric restriction and age on activities," Bioscience Reports, vol. 28, no. 2, pp. 107-115, 2008.

[163] S. Summermatter, D. Mainieri, A. P. Russell et al., "Thrifty metabolism that favors fat storage after caloric restriction: a role for skeletal muscle phosphatidylinositol-3-kinase activity and AMP-activated protein kinase," The FASEB Journal, vol. 22, no. 3, pp. 774-785, 2008.

[164] P. B. M. De Andrade, L. A. Neff, M. K. Strosova et al., "Caloric restriction induces energy-sparing alterations in skeletal muscle contraction, fiber composition and local thyroid hormone metabolism that persist during catch-up fat upon refeeding," Frontiers in Physiology, vol. 6, 2015.

[165] D. W. Lamming and R. M. Anderson, "Metabolic effects of caloric restriction," in eLS. Chichester, John Wiley \& Sons Ltd, 2014.

[166] A. J. Donato, A. E. Walker, K. A. Magerko et al., "Life-long caloric restriction reduces oxidative stress and preserves nitric oxide bioavailability and function in arteries of old mice," Aging Cell, vol. 12, no. 5, pp. 772-783, 2013.

[167] X. Qiu, K. Brown, M. D. Hirschey, E. Verdin, and D. Chen, "Calorie restriction reduces oxidative stress by SIRT3mediated SOD2 activation," Cell Metabolism, vol. 12, no. 6, pp. 662-667, 2010.

[168] A. R. Heydari, A. Unnikrishnan, L. V. Lucente, and A. Richardson, "Caloric restriction and genomic stability," Nucleic Acids Research, vol. 35, no. 22, pp. 7485-7496, 2007.

[169] W. E. Sonntag, C. D. Lynch, W. T. Cefalu et al., "Pleiotropic effects of growth hormone and insulin-like growth factor (IGF)-1 on biological aging: inferences from moderate caloric-restricted animals," The Journals of Gerontology Series A: Biological Sciences and Medical Sciences, vol. 54, no. 12, pp. B521-B538, 1999.

[170] I. Shimokawa, Y. Higami, T. Tsuchiya et al., "Life span extension by reduction of the growth hormone-insulin-like growth factor-1 axis: relation to caloric restriction," The FASEB Journal, vol. 17, no. 9, pp. 1108-1109, 2003.

[171] S. D. Hursting, S. M. Smith, L. M. Lashinger, A. E. Harvey, and S. N. Perkins, "Calories and carcinogenesis: lessons learned from 30 years of calorie restriction research," Carcinogenesis, vol. 31, no. 1, pp. 83-89, 2010.

[172] J. H. Um, S. J. Kim, D. W. Kim et al., "Tissue-specific changes of DNA repair protein $\mathrm{Ku}$ and $\mathrm{mtHSP70}$ in aging rats and their retardation by caloric restriction," Mechanisms of Ageing and Development, vol. 124, no. 8-9, pp. 967-975, 2003.

[173] D. C. Cabelof, S. Yanamadala, J. J. Raffoul, Z. Guo, A. Soofi, and A. R. Heydari, "Caloric restriction promotes genomic stability by induction of base excision repair and reversal of its age-related decline," DNA Repair, vol. 2, no. 3, pp. 295307, 2003.

[174] V. Calabrese, C. Cornelius, S. Cuzzocrea, I. Iavicoli, E. Rizzarelli, and E. J. Calabrese, "Hormesis, cellular stress response and vitagenes as critical determinants in aging and longevity," Molecular Aspects of Medicine, vol. 32, no. 4-6, pp. 279-304, 2011.

[175] M. V. Blagosklonny, "Calorie restriction: decelerating mTOR-driven aging from cells to organisms (including humans)," Cell Cycle, vol. 9, no. 4, pp. 683-688, 2014.
[176] S. Robida-Stubbs, K. Glover-Cutter, D. W. Lamming et al., "TOR signaling and rapamycin influence longevity by regulating SKN-1/Nrf and DAF-16/FoxO," Cell Metabolism, vol. 15, no. 5, pp. 713-724, 2012.

[177] S. L. Hands, C. G. Proud, and A. Wyttenbach, "mTOR's role in ageing: protein synthesis or autophagy?," Aging, vol. 1, no. 7, pp. 586-597, 2009.

[178] C. H. Jung, S.-H. Ro, J. Cao, N. M. Otto, and D.-H. Kim, "mTOR regulation of autophagy," FEBS Letters, vol. 584, no. 7, pp. 1287-1295, 2010.

[179] M. Kaeberlein, R. W. Powers 3rd, K. K. Steffen et al., "Regulation of yeast replicative life span by TOR and Sch9 in response to nutrients," Science, vol. 310, no. 5751, pp. 1193-1196, 2005.

[180] P. Kapahi, B. M. Zid, T. Harper, D. Koslover, V. Sapin, and S. Benzer, "Regulation of lifespan in Drosophila by modulation of genes in the TOR signaling pathway," Current Biology, vol. 14, no. 10, pp. 885-890, 2004.

[181] T. Vellai, K. Takacs-Vellai, Y. Zhang, A. L. Kovacs, L. Orosz, and F. Muller, "Genetics: influence of TOR kinase on lifespan in C. elegans," Nature., vol. 426, no. 6967, p. 620, 2003.

[182] L. Fontana, L. Partridge, and V. D. Longo, "Extending healthy life span-from yeast to humans," Science, vol. 328, no. 5976, pp. 321-326, 2010.

[183] C. Slack, M. E. Giannakou, A. Foley, M. Goss, and L. Partridge, "dFOXO-independent effects of reduced insulin-like signaling in Drosophila," Aging Cell, vol. 10, no. 5, pp. 735-748, 2011.

[184] A. Ortega-Molina, A. Efeyan, E. Lopez-Guadamillas et al., "Pten positively regulates brown adipose function, energy expenditure, and longevity," Cell Metabolism, vol. 15, no. 3, pp. 382-394, 2012.

[185] M. M. Mihaylova and R. J. Shaw, "The AMPK signalling pathway coordinates cell growth, autophagy and metabolism," Nature Cell Biology, vol. 13, no. 9, pp. 1016-1023, 2011.

[186] D. G. Hardie, “AMP-activated protein kinase: an energy sensor that regulates all aspects of cell function," Genes \& Development, vol. 25, no. 18, pp. 1895-1908, 2011.

[187] G. R. Steinberg and B. E. Kemp, "AMPK in health and disease," Physiological Reviews, vol. 89, no. 3, pp. 1025-1078, 2009.

[188] B. Onken and M. Driscoll, "Metformin induces a dietary restriction-like state and the oxidative stress response to extend C. elegans healthspan via AMPK, LKB1, and SKN1," PLoS One, vol. 5, no. 1, article e8758, 2010.

[189] J. Apfeld, G. O'Connor, T. McDonagh, P. S. DiStefano, and R. Curtis, "The AMP-activated protein kinase AAK-2 links energy levels and insulin-like signals to lifespan in C. elegans," Genes \& Development, vol. 18, no. 24, pp. 3004-3009, 2004.

[190] V. N. Anisimov, "Metformin for cancer and aging prevention: is it a time to make the long story short?," Oncotarget, vol. 6, no. 37, pp. 39398-39407, 2015.

[191] M. Sorensen, A. Sanz, J. Gomez et al., "Effects of fasting on oxidative stress in rat liver mitochondria," Free Radical Research, vol. 40, no. 4, pp. 339-347, 2009.

[192] A. B. Crujeiras, D. Parra, E. Goyenechea, and J. A. Martinez, "Sirtuin gene expression in human mononuclear cells is modulated by caloric restriction," Eur J Clin Invest., vol. 38, no. 9, pp. 672-678, 2008.

[193] S. Someya, W. Yu, W. C. Hallows et al., "Sirt3 mediates reduction of oxidative damage and prevention of age-related 
hearing loss under caloric restriction," Cell, vol. 143, no. 5, pp. 802-812, 2010.

[194] S. Michan and D. Sinclair, "Sirtuins in mammals: insights into their biological function," Biochemical Journal, vol. 404, no. 1, pp. 1-13, 2007.

[195] M. T. Borra, B. C. Smith, and J. M. Denu, "Mechanism of human SIRT1 activation by resveratrol," Journal of Biological Chemistry, vol. 280, no. 17, pp. 17187-17195, 2005.

[196] M. Gertz, G. T. T. Nguyen, F. Fischer et al., "A molecular mechanism for direct sirtuin activation by resveratrol," PLoS One, vol. 7, no. 11, article e49761, 2012.

[197] B. Dasgupta and J. Milbrandt, "Resveratrol stimulates AMP kinase activity in neurons," Proceedings of the National Academy of Sciences, vol. 104, no. 17, pp. 72177222, 2007.

[198] L. M. V. de Almeida, M. C. Leite, A. P. Thomazi et al., "Resveratrol protects against oxidative injury induced by $\mathrm{H} 2 \mathrm{O} 2$ in acute hippocampal slice preparations from Wistar rats," Archives of Biochemistry and Biophysics, vol. 480, no. 1, pp. 27-32, 2008.

[199] L. M. V. de Almeida, C. C. Piñeiro, M. C. Leite et al., "Protective effects of resveratrol on hydrogen peroxide induced toxicity in primary cortical astrocyte cultures," Neurochemical Research, vol. 33, no. 1, pp. 8-15, 2008.

[200] L. Liu, L. Gu, Q. Ma, D. Zhu, and X. Huang, "Resveratrol attenuates hydrogen peroxide-induced apoptosis in human umbilical vein endothelial cells," European Review for Medical and Pharmacological Sciences, vol. 17, no. 1, pp. 88-94, 2013.

[201] L. M. V. de Almeida, C. C. Piñeiro, M. C. Leite et al., "Resveratrol increases glutamate uptake, glutathione content, and S100B secretion in cortical astrocyte cultures," Cellular and Molecular Neurobiology, vol. 27, no. 5, pp. 661-668, 2007.

[202] J. Chang, J. E. Cornell, H. Van Remmen, K. Hakala, W. F. Ward, and A. Richardson, "Effect of aging and caloric restriction on the mitochondrial proteome," The Journals of Gerontology Series A: Biological Sciences and Medical Sciences, vol. 62, no. 3, pp. 223-234, 2007.

[203] G. López-Lluch, N. Hunt, B. Jones et al., "Calorie restriction induces mitochondrial biogenesis and bioenergetic efficiency," Proceedings of the National Academy of Sciences, vol. 103, no. 6, pp. 1768-1773, 2006.

[204] Z. Ungvari, C. Parrado-Fernandez, A. Csiszar, and R. de Cabo, "Mechanisms underlying caloric restriction and lifespan regulation: implications for vascular aging," Circulation Research, vol. 102, no. 5, pp. 519-528, 2008.

[205] L. Guarente, "NO link between calorie restriction and mitochondria," Nature Chemical Biology, vol. 1, no. 7, pp. 355356, 2005.

[206] A. Richardson, S. N. Austad, Y. Ikeno, A. Unnikrishnan, and R. J. McCarter, "Significant life extension by ten percent dietary restriction," Annals of the New York Academy of Sciences, vol. 1363, no. 1, pp. 11-17, 2016.

[207] Y. Zhang, Y. Ikeno, A. Bokov et al., "Dietary restriction attenuates the accelerated aging phenotype of Sod1 $1^{-1-}$ mice," Free Radical Biology and Medicine, vol. 60, pp. 300-306, 2013.

[208] Y. C. Jang, Y. Liu, C. R. Hayworth et al., "Dietary restriction attenuates age-associated muscle atrophy by lowering oxidative stress in mice even in complete absence of CuZnSOD," Aging Cell, vol. 11, no. 5, pp. 770-782, 2012.
[209] M. Meydani and W. J. Evans, "Free radicals, exercise, and aging," in Free Radicals in Aging, B. P. Yu, Ed., pp. 183-204, CRC Press, Boca Raton, 1993.

[210] L. L. Ji, "Antioxidants and oxidative stress in exercise," Proceedings of the Society for Experimental Biology and Medicine, vol. 222, no. 3, pp. 283-292, 1999.

[211] J. Bejma, P. R. Ramires, C. Donahue, and L. L. Ji, “Aging and acute exercise enhances free radical generation and oxidative damage in skeletal muscle," Medicine \& Science in Sports \& Exercise, vol. 30, Supplement, p. 322, 1998.

[212] M.-C. Gomez-Cabrera, C. Borrás, F. V. Pallardó, J. Sastre, L. L. Ji, and J. Viña, "Decreasing xanthine oxidase-mediated oxidative stress prevents useful cellular adaptations to exercise in rats," The Journal of Physiology, vol. 567, no. 1, pp. 113-120, 2005.

[213] M. A. Naseeb and S. L. Volpe, "Protein and exercise in the prevention of sarcopenia and aging," Nutrition Research, vol. 40, pp. 1-20, 2017.

[214] A. T. Ludlow and S. M. Roth, "Physical activity and telomere biology: exploring the link with aging-related disease prevention," Journal of Aging Research, vol. 2011, Article ID 790378, 12 pages, 2011.

[215] B. Hurley and I. Reuter, "Aging, physical activity, and disease prevention," Journal of Aging Research, vol. 2011, Article ID 782546, 2 pages, 2011.

[216] N. Garatachea, H. Pareja-Galeano, F. Sanchis-Gomar et al., "Exercise attenuates the major hallmarks of aging," Rejuvenation Research, vol. 18, no. 1, pp. 57-89, 2015.

[217] J. Hollander, J. Bejma, T. Ookawara, H. Ohno, and L. L. Ji, "Superoxide dismutase gene expression in skeletal muscle: fiber-specific effect of age," Mechanisms of Ageing and Development, vol. 116, no. 1, pp. 33-45, 2000.

[218] A. McArdle and M. J. Jackson, "Exercise, oxidative stress and ageing," Journal of Anatomy, vol. 197, no. 4, pp. 539-541, 2000.

[219] Y.-J. Kim and D. M. Wilson III, "Overview of base excision repair biochemistry," Current Molecular Pharmacology, vol. 5, no. 1, pp. 3-13, 2012.

[220] M. Bar-Shai, E. Carmeli, and A. Z. Reznick, "The role of $\mathrm{NF}-\kappa \mathrm{B}$ in protein breakdown in immobilization, aging, and exercise: from basic processes to promotion of health," Annals of the New York Academy of Sciences, vol. 1057, no. 1, pp. 431-447, 2005.

[221] Z. Radak, H. Y. Chung, E. Koltai, A. W. Taylor, and S. Goto, "Exercise, oxidative stress and hormesis," Ageing Research Reviews, vol. 7, no. 1, pp. 34-42, 2008.

[222] Z. Radak, H. Y. Chung, and S. Goto, "Exercise and hormesis: oxidative stress-related adaptation for successful aging," Biogerontology, vol. 6, no. 1, pp. 71-75, 2005.

[223] L. L. Ji, "Antioxidant signaling in skeletal muscle: a brief review," Experimental Gerontology, vol. 42, no. 7, pp. 582593, 2007.

[224] B. Chance, H. Sies, and A. Boveris, "Hydroperoxide metabolism in mammalian organs," Physiological Reviews, vol. 59, no. 3, pp. 527-605, 1979.

[225] T. Akimoto, S. C. Pohnert, P. Li et al., "Exercise stimulates Pgc- $1 \alpha$ transcription in skeletal muscle through activation of the p38 MAPK pathway," Journal of Biological Chemistry, vol. 280, no. 20, pp. 19587-19593, 2005.

[226] J. St-Pierre, S. Drori, M. Uldry et al., "Suppression of reactive oxygen species and neurodegeneration by the PGC-1 
transcriptional coactivators," Cell, vol. 127, no. 2, pp. 397408, 2006.

[227] L. L. Ji, "Exercise at old age: does it increase or alleviate oxidative stress?," Annals of the New York Academy of Sciences, vol. 928, pp. 236-247, 2001.

[228] Z. Radák, H. Y. Chung, H. Naito et al., “Age-associated increase in oxidative stress and nuclear factor $\kappa \mathrm{B}$ activation are attenuated in rat liver by regular exercise," The FASEB Journal, vol. 18, no. 6, pp. 749-750, 2004.

[229] C. S. Broome, A. C. Kayani, J. Palomero et al., "Effect of lifelong overexpression of HSP70 in skeletal muscle on agerelated oxidative stress and adaptation after nondamaging contractile activity," The FASEB Journal, vol. 20, no. 9, pp. 1549-1551, 2006.

[230] T. A. Hornberger, R. D. Mateja, E. R. Chin, J. L. Andrews, and K. A. Esser, "Aging does not alter the mechanosensitivity of the p38, p70S6k, and JNK2 signaling pathways in skeletal muscle," Journal of Applied Physiology, vol. 98, no. 4, pp. 1562-1566, 2005.

[231] D. Williamson, P. Gallagher, M. Harber, C. Hollon, and S. Trappe, "Mitogen-activated protein kinase (MAPK) pathway activation: effects of age and acute exercise on human skeletal muscle," The Journal of Physiology, vol. 547, no. 3, pp. 977-987, 2003.

[232] M. Gleeson, N. C. Bishop, D. J. Stensel, M. R. Lindley, S. S. Mastana, and M. A. Nimmo, "The anti-inflammatory effects of exercise: mechanisms and implications for the prevention and treatment of disease," Nature Reviews Immunology, vol. 11, no. 9, pp. 607-615, 2011.

[233] I. Gath, E. I. Closs, U. Gödtel-Armbrust et al., "Inducible NO synthase II and neuronal NO synthase I are constitutively expressed in different structures of guinea pig skeletal muscle: implications for contractile function," The FASEB Journal, vol. 10, no. 14, pp. 1614-1620, 1996.

[234] M. R. Rose, Evolutionary biology of aging, Oxford University Press, Oxford, UK, 1994.

[235] M. Ackermann, S. C. Stearns, and U. Jenal, "Senescence in a bacterium with asymmetric division," Science, vol. 300, no. 5627, p. 1920, 2003.

[236] M. Ackermann, L. Chao, C. T. Bergstrom, and M. Doebeli, "On the evolutionary origin of aging," Aging Cell, vol. 6, no. 2, pp. 235-244, 2007.

[237] E. J. Stewart, R. Madden, G. Paul, and F. Taddei, “Aging and death in an organism that reproduces by morphologically symmetric division," PLoS Biology, vol. 3, no. 2, article e45, 2005.

[238] J.-W. J. Veening, E. J. Stewart, T. W. Berngruber, F. Taddei, O. P. Kuipers, and L. W. Hamoen, "Bet-hedging and epigenetic inheritance in bacterial cell development," Proceedings of the National Academy of Sciences, vol. 105, no. 11, pp. 4393-4398, 2008.

[239] B. B. Aldridge, M. Fernandez-Suarez, D. Heller et al., "Asymmetry and aging of mycobacterial cells lead to variable growth and antibiotic susceptibility," Science, vol. 335, no. 6064, pp. 100-104, 2012.

[240] T. Nyström, "Conditional senescence in bacteria: death of the immortals," Molecular Microbiology, vol. 48, no. 1, pp. 17-23, 2003.

[241] K. A. Steinkraus, M. Kaeberlein, and B. K. Kennedy, "Replicative aging in yeast: the means to the end," Annual
Review of Cell and Developmental Biology, vol. 24, no. 1, pp. 29-54, 2008.

[242] J. Winkler, A. Seybert, L. König et al., "Quantitative and spatio-temporal features of protein aggregation in Escherichia coli and consequences on protein quality control and cellular ageing," The EMBO Journal, vol. 29, no. 5, pp. 910923, 2010.

[243] A. B. Lindner, R. Madden, A. Demarez, E. J. Stewart, and F. Taddei, "Asymmetric segregation of protein aggregates is associated with cellular aging and rejuvenation," Proceedings of the National Academy of Sciences, vol. 105, no. 8, pp. 30763081, 2008.

[244] M. Coelho and I. M. Tolic, "Asymmetric damage segregation at cell division via protein aggregate fusion and attachment to organelles," Bioessays, vol. 37, no. 7, pp. 740-747, 2015.

[245] R. Higuchi-Sanabria, W. M. A. Pernice, J. D. Vevea, D. M. Alessi Wolken, I. R. Boldogh, and L. A. Pon, "Role of asymmetric cell division in lifespan control in Saccharomyces cerevisiae," FEMS Yeast Research, vol. 14, no. 8, pp. 1133-1146, 2014.

[246] H. Aguilaniu, L. Gustafsson, M. Rigoulet, and T. Nyström, "Asymmetric inheritance of oxidatively damaged proteins during cytokinesis,” Science, vol. 299, no. 5613, pp. 17511753, 2003.

[247] A.-S. Coquel, J.-P. Jacob, M. Primet et al., "Localization of protein aggregation in Escherichia coli is governed by diffusion and nucleoid macromolecular crowding effect," PLoS Computational Biology, vol. 9, no. 4, article e1003038, 2013.

[248] B. Desnues, C. Cuny, G. Grégori, S. Dukan, H. Aguilaniu, and T. Nyström, "Differential oxidative damage and expression of stress defence regulons in culturable and non-culturable Escherichia coli cells," EMBO Reports, vol. 4, no. 4, pp. 400404, 2003.

[249] I. Dalle-Donne, G. Aldini, M. Carini, R. Colombo, R. Rossi, and A. Milzani, "Protein carbonylation, cellular dysfunction, and disease progression," Journal of Cellular and Molecular Medicine, vol. 10, no. 2, pp. 389-406, 2006.

[250] I. Dalle-Donne, D. Giustarini, R. Colombo, R. Rossi, and A. Milzani, "Protein carbonylation in human diseases," Trends in Molecular Medicine, vol. 9, no. 4, pp. 169-176, 2003.

[251] T. Nyström, "The free-radical hypothesis of aging goes prokaryotic," Cellular and Molecular Life Sciences (CMLS), vol. 60, no. 7, pp. 1333-1341, 2003.

[252] A. L. Santos, V. Oliveira, I. Baptista et al., "Wavelength dependence of biological damage induced by UV radiation on bacteria," Archives of Microbiology, vol. 195, no. 1, pp. 63-74, 2013.

[253] F. Bosshard, K. Riedel, T. Schneider, C. Geiser, M. Bucheli, and T. Egli, "Protein oxidation and aggregation in UVAirradiated Escherichia coli cells as signs of accelerated cellular senescence," Environmental Microbiology, vol. 12, no. 11, pp. 2931-2945, 2010.

[254] S. Dukan, T. Nyström, and T. Nystro, "Oxidative stress defense and deterioration of growth-arrested Escherichia coli cells," Journal of Biological Chemistry, vol. 274, no. 37, pp. 26027-26032, 1999.

[255] F. B. Johnson, D. A. Sinclair, and L. Guarente, "Molecular biology of aging," Cell, vol. 96, no. 2, pp. 291-302, 1999. 
[256] S. Dukan and T. Nyström, "Bacterial senescence: stasis results in increased and differential oxidation of cytoplasmic proteins leading to developmental induction of the heat shock regulon," Genes \& Development, vol. 12, no. 21, pp. 34313441, 1998.

[257] J. Tamarit, E. Cabiscol, and J. Ros, "Identification of the major oxidatively damaged proteins in Escherichia coli cells exposed to oxidative stress," Journal of Biological Chemistry, vol. 273, no. 5, pp. 3027-3032, 1998.

[258] E. Cabiscol, E. Piulats, P. Echave, E. Herrero, and J. Ros, "Oxidative stress promotes specific protein damage in Saccharomyces cerevisiae," Journal of Biological Chemistry, vol. 275, no. 35, pp. 27393-27398, 2000.

[259] R. S. Sohal, "Role of oxidative stress and protein oxidation in the aging process," Free Radical Biology and Medicine, vol. 33, no. 1, pp. 37-44, 2002.

[260] L.-J. Yan, R. L. Levine, and R. S. Sohal, "Oxidative damage during aging targets mitochondrial aconitase," Proceedings of the National Academy of Sciences, vol. 94, no. 21, pp. 11168-11172, 1997.

[261] A. Castegna, M. Aksenov, M. Aksenova et al., "Proteomic identification of oxidatively modified proteins in Alzheimer's disease brain. Part I: Creatine kinase BB, glutamine synthase, and ubiquitin carboxy-terminal hydrolase L-1," Free Radical Biology and Medicine, vol. 33, no. 4, pp. 562-571, 2002.

[262] A. Matin, "The molecular basis of carbon-starvation-induced general resistance in Escherichia coli," Molecular Microbiology, vol. 5, no. 1, pp. 3-10, 1991.

[263] D. E. Jenkins, J. E. Schultz, and A. Matin, "Starvation-induced cross protection against heat or $\mathrm{H} 2 \mathrm{O} 2$ challenge in Escherichia coli," Journal of Bacteriology, vol. 170, no. 9, pp. 39103914, 1988.

[264] R. A. Miller, "Cell stress and aging: new emphasis on multiplex resistance mechanisms," The Journals of Gerontology Series A: Biological Sciences and Medical Sciences, vol. 64A, no. 2, pp. 179-182, 2009.

[265] L. E. Enell, N. Kapan, J. A. E. Soderberg, L. Kahsai, and D. R. Nassel, "Insulin signaling, lifespan and stress resistance are modulated by metabotropic GABA receptors on insulin producing cells in the brain of Drosophila," PLoS One, vol. 5, no. 12, article e15780, 2010.

[266] S. Ayyadevara, M. R. Engle, S. P. Singh et al., "Lifespan and stress resistance of Caenorhabditis elegans are increased by expression of glutathione transferases capable of metabolizing the lipid peroxidation product 4-hydroxynonenal," Aging Cell, vol. 4, no. 5, pp. 257-271, 2005.

[267] M. Shaposhnikov, E. Proshkina, L. Shilova, A. Zhavoronkov, and A. Moskalev, "Lifespan and stress resistance in Drosophila with overexpressed DNA repair genes," Scientific Reports, vol. 5, no. 1, article 15299, 2015.

[268] V. D. Longo, J. Mitteldorf, and V. P. Skulachev, "Programmed and altruistic ageing," Nature Reviews Genetics, vol. 6, no. 11, pp. 866-872, 2005.

[269] M. Ballesteros, A. Fredriksson, J. Henriksson, and T. Nyström, "Bacterial senescence: protein oxidation in non-proliferating cells is dictated by the accuracy of the ribosomes," The EMBO Journal, vol. 20, no. 18, pp. 5280-5289, 2001.

[270] H. Aguilaniu, L. Gustafsson, M. Rigoulet, and T. Nyström, "Protein oxidation in G0 cells of Saccharomyces cerevisiae depends on the state rather than rate of respiration and is enhanced in pos 9 but not yap1 mutants," Journal of Biological Chemistry, vol. 276, no. 38, pp. 35396-35404, 2001.

[271] T. Nyström, "Not quite dead enough: on bacterial life, culturability, senescence, and death," Archives of Microbiology, vol. 176, no. 3, pp. 159-164, 2001.

[272] A. Battesti, N. Majdalani, and S. Gottesman, "The RpoSmediated general stress response in Escherichia coli," Annual Review of Microbiology, vol. 65, no. 1, pp. 189-213, 2011.

[273] T. L. Testerman, A. Vazquez-Torres, Y. Xu, J. Jones-Carson, S. J. Libby, and F. C. Fang, "The alternative sigma factor $\sigma^{\mathrm{E}}$ controls antioxidant defences required for Salmonella virulence and stationary-phase survival," Molecular Microbiology, vol. 43, no. 3, pp. 771-782, 2002.

[274] F. Fontaine, E. J. Stewart, A. B. Lindner, and F. Taddei, "Mutations in two global regulators lower individual mortality in Escherichia coli," Molecular Microbiology, vol. 0, no. 0, pp. 2-14, 2007.

[275] S. Gonidakis, S. E. Finkel, and V. D. Longo, "Genome-wide screen identifies Escherichia coli TCA-cycle-related mutants with extended chronological lifespan dependent on acetate metabolism and the hypoxia-inducible transcription factor ArcA," Aging Cell, vol. 9, no. 5, pp. 868-881, 2010.

[276] L. Yu and C. Yu, "Interaction between succinate dehydrogenase and ubiquinone-binding protein from succinateubiquinone reductase," Biochimica et Biophysica Acta (BBA) - Bioenergetics, vol. 593, no. 1, pp. 24-38, 1980.

[277] K. R. Messner and J. A. Imlay, "Mechanism of superoxide and hydrogen peroxide formation by fumarate reductase, succinate dehydrogenase, and aspartate oxidase," Journal of Biological Chemistry, vol. 277, no. 45, pp. 42563-42571, 2002.

[278] S. Gonidakis, S. E. Finkel, and V. D. Longo, "E. coli hypoxiainducible factor ArcA mediates lifespan extension in a lipoic acid synthase mutant by suppressing acetyl-CoA synthetase," Biological Chemistry, vol. 391, no. 10, pp. 1139-1147, 2010.

[279] A. S. Lynch and E. C. Lin, "Transcriptional control mediated by the ArcA two-component response regulator protein of Escherichia coli: characterization of DNA binding at target promoters," Journal of Bacteriology, vol. 178, no. 21, pp. 6238-6249, 1996. 


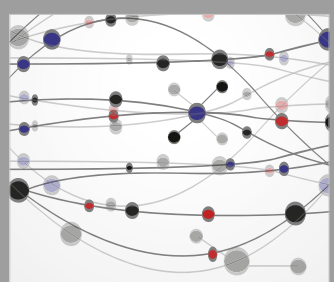

The Scientific World Journal
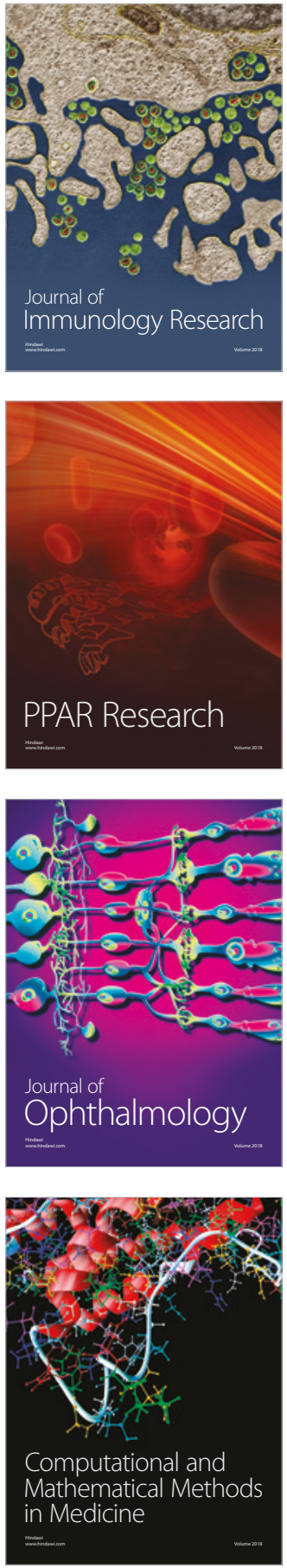

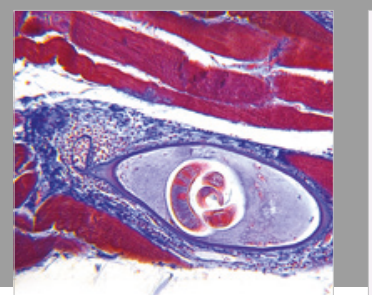

Gastroenterology Research and Practice

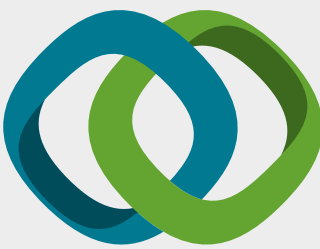

\section{Hindawi}

Submit your manuscripts at

www.hindawi.com
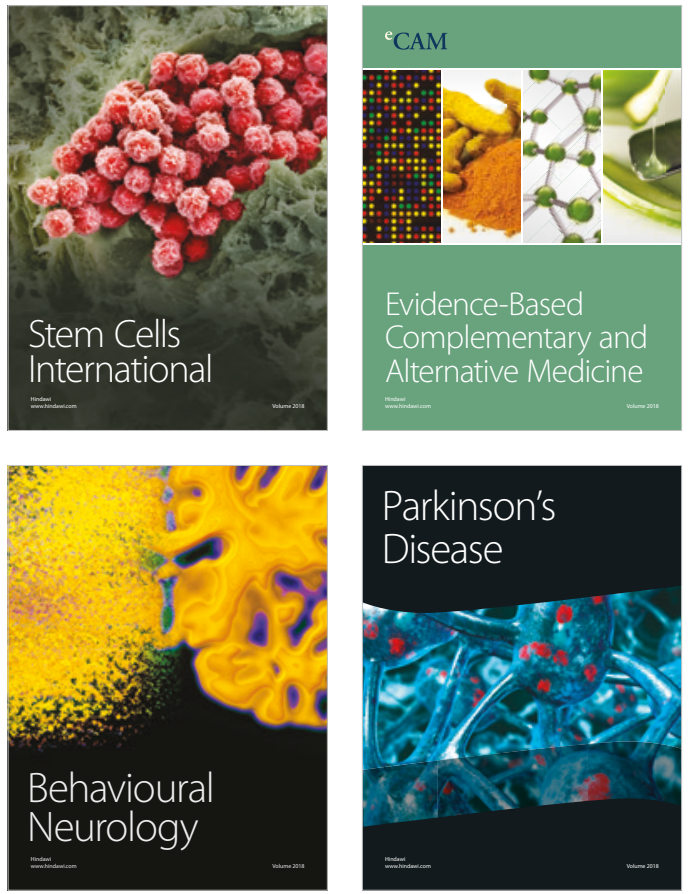

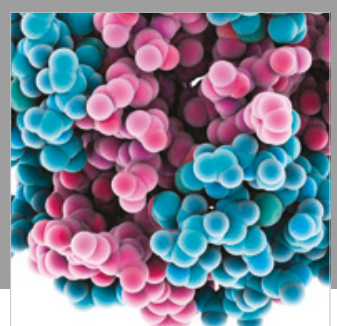

ournal of

Diabetes Research

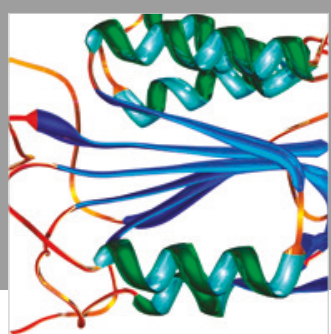

Disease Markers
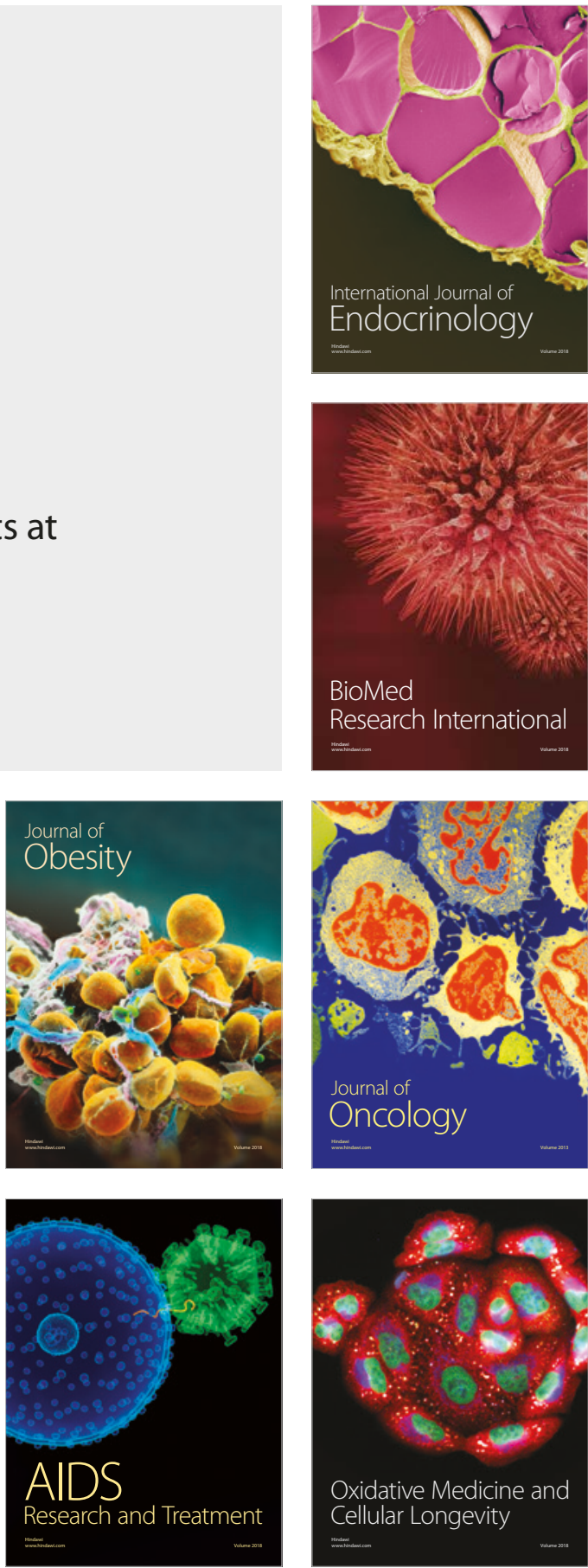